\title{
Studies on Optimal Strategy to Adopt Nuclear Power Plants into Saudi Arabian Energy System Using MESSAGE Tool
}

\author{
Shadwan M. M. Esmail $\mathbb{D}$ and Jae Hak Cheong $\mathbb{B}$ \\ Department of Nuclear Engineering, Kyung Hee University, 1732, Deogyeong-daero, Giheung-gu, Yongin-si, Gyeonggi-do 17104, \\ Republic of Korea \\ Correspondence should be addressed to Jae Hak Cheong; jhcheong@khu.ac.kr
}

Received 14 August 2020; Revised 12 March 2021; Accepted 23 April 2021; Published 3 May 2021

Academic Editor: Guglielmo Lomonaco

Copyright (C) 2021 Shadwan M. M. Esmail and Jae Hak Cheong. This is an open access article distributed under the Creative Commons Attribution License, which permits unrestricted use, distribution, and reproduction in any medium, provided the original work is properly cited.

\begin{abstract}
An optimal long-term electric power strategy for Saudi Arabia to adopt nuclear power was evaluated using the MESSAGE tool. Saudi Arabia is predicted to experience an electricity shortage by 2025 with the present energy system. This electricity shortage could be postponed until 2035 by rehabilitating the existing power plants. The MESSAGE model predicts that adopting a combination of renewable (i.e., solar and wind), advanced traditional power (i.e., gas turbine, steam, and combined cycle), and nuclear technologies is the most competitive future strategy to supply $43.7 \%, 41.6 \%$, and $3.8 \%$, respectively, of Saudi Arabia's electricity needs by 2050 . This paper proposes an optimal strategy for adopting nuclear power. The nuclear capacity of three scenarios was evaluated: a single APR-1400 nuclear reactor, a single SMART-100 nuclear reactor, and a combination of these two reactors. The results of this study indicate that the highest nuclear capacity was achieved by the combination of the APR-1400 and SMART-100 reactors followed by the single APR-1400 reactor and then the single SMART-100 reactor. However, the single G4ECONS nuclear reactor shows a higher capacity than the single APR-1400 reactor in other evaluated scenarios. The combined reactor strategy may be the most feasible option if the capital cost of a first-of-a-kind SMART-100 reactor is reduced by $62.3 \%$. The cost reductions result from including factors like the time required to build the nuclear power plants in the MESSAGE tool calculation. Also, $\mathrm{CO}_{2}$ taxation will increase nuclear power's feasibility in the Saudi Arabian energy system. However, the share of renewable energy is predicted to be more affected by the taxation of $\mathrm{CO}_{2}$. In this study, the proposed approach can provide more flexible strategic options for countries embarking on nuclear energy. These flexible strategic options can optimize their national energy mix for long-term planning.
\end{abstract}

\section{Introduction}

Energy, including electricity, plays a crucial role in the economic growth and social development of Saudi Arabia. Although Saudi Arabia has been the world's largest oil producer and exporter [1], previous studies predict that Saudi Arabia will be a net oil importer by 2030 or 2038. This will happen unless appropriate measures for the development of sustainable energy systems are immediately undertaken [2'3]. Currently, Saudi Arabia ranks $11^{\text {th }}$ in the world in electric power production and $13^{\text {th }}$ in the world in electricity consumption [4]. The Saudi Electric Company was the $14^{\text {th }}$ biggest electricity company in the world at the end of September 2017 [5].
In 2015, Saudi Arabia had more than 940 generator units in 46 power plants (PPs) distributed over four geographical regions (i.e., load areas) [6]. However, more PPs are needed to match its rapidly expanding electricity demand rate. This electricity demand rate is predicted to increase annually by $5 \%-8 \%$ [7-9]. It is reported that desalination of water significantly affects the energy Equation in the Middle East. Desalination of water is required more in the Middle East than in any other part of the world. Thus, energy and water are closely intertwined in the Middle East. In this region, any discussion about the outlook of electricity also becomes a discussion about water. The Middle East uses desalination to narrow the gap between freshwater withdrawals and a sustainable water supply [10]. 
Saudi Arabia uses $25 \%-50 \%$ of its oil and gas production to desalinate water. This means that the desalination sector uses a significant portion of Saudi Arabia's energy capacity [11-15]. In Saudi Arabia, the installed power capacity is expected to grow at an annual capacity growth rate of approximately $1.5 \%$ from 2020 to 2025 . However, the energy demand is expected to increase by $8 \%-10 \%$ annually. Peak demand was $70 \mathrm{GW}$ in 2020 . This peak demand is expected to reach $120 \mathrm{GW}$ by 2032, partially driven by increased water desalination. The region's unstable geopolitics are expected to act as a restraint on market growth in the power sector. In 2014, Saudi Arabia was estimated to increase its power generation capacity from $77 \mathrm{GW}$ in 2014 to $156 \mathrm{GW}$ in 2040 [8-12]. A recent study reports that desalination of water production has reached $2559 \mathrm{Mm}^{3}$, with an annual growth rate of 5\% in Saudi Arabia. Consequently, sustaining and improving the capacity of domestic PPs has become a major challenge in Saudi Arabia. Currently, approximately $60 \%$ of Saudi Arabia's total electricity supply is generated by burning oil in the planning and management of electric power generation systems [16].

Reduction in greenhouse gases (e.g., $\mathrm{CO}_{2}$ ) produced by PPs is a strategic objective of Saudi Arabia. Currently, Saudi Arabia is the $10^{\text {th }}$ largest greenhouse gas-emitting country in the world [17]. This study evaluated possible electricity generation techniques to meet the future demand for clean energy in Saudi Arabia.

Previous studies on Saudi Arabia energy systems only evaluated short-term (e.g., 5 to 15 years) or medium-term (e.g., 20 to 30 years) electricity demands. The existing studies focused on the potential applications of new technologies, including wind and geothermal energy [18'19]. These studies compared some renewable energy technologies with existing energy technologies [20'21]. However, these previous studies did not comprehensively evaluate the options for future energy systems in Saudi Arabia (e.g., utilization of existing PPs and strategic introduction of new technologies in the PPs, such as coal, waste, nuclear, and advanced traditional fuel).

A recent study showed planned nuclear power plants (NPPs) in the Middle East and North Africa region. This study identified Iran, UAE, Egypt, and Jordan as countries possibly adopting nuclear technology [22]. Although Saudi Arabia plans to introduce NPPs in the near future, this paper categorizes Saudi Arabia as a country expressing nuclear intention and does not directly address any specific nuclear power development plans. However, some technical or economic studies on Saudi Arabia energy policy have mentioned that nuclear power is one of the main options in the future power system by the Nuclear Energy Development Road Map (NEDRM). Saudi Arabia is included in the NEDRM timetable for the development of NPPs [7'23'24].

Based on the NEDRM, Saudi Arabia originally planned to construct 12 units of NPPs over the next three decades. The site selection process was set to begin in 2013. Construction of the NPPS was set to start in 2017. The first NPP was scheduled to start operating by 2022. Five NPPs were scheduled for construction by 2027. These NPPs were expected to produce an accumulated total capacity of 9.6 GWe.
An additional six NPPs were planned to be installed by 2032 . By 2032, the total capacity of NPPs was projected to reach 17 or 17.6 GWe [7'24].

A recent report mentioned that the nuclear target date has now been delayed until 2040 [25]. In 2019, the King Abdullah City for Atomic and Renewable Energy (KA-CARE) announced plans for a new renewable target. These plans included a target of 2032 to produce 58.7 GWe by renewable technologies [26]. Some recent studies discussed that using electricity produced by solar and wind technologies in a grid may cause problems at high demand levels. These problems occur because the supply of electricity produced by these technologies does not correspond to the demand $[27,28]$. In March 2015, the Korea Atomic Energy Research Institute (KAERI) signed a Memorandum of Understanding with the KA-CARE. Under this agreement, the two countries conducted a three-year preliminary study to review the feasibility of constructing SMART-100 reactors in Saudi Arabia. The agreement anticipated that the cost of building the first SMART-100 unit in Saudi Arabia was one billion USD. The contract to build four advanced power reactors (APRs) at Barakah with a nameplate capacity of 5,380 MWe had cost estimates ranging from 24.4 to 32 billion USD [9, 29-32]. Additionally, the SMART-100 supply chain and potential success were compared to projections for four Korean Electric Power Company APR-1400s currently being built in the United Arab Emirates (UAE) [31].

However, the NEDRM did not specify the available nuclear power development programs in Saudi Arabia. To date, there have not been any updated reports with additional detailed information (e.g., schedule of deployment of NPPs, time-dependent nuclear share, and type or capacity of NPPs to be built) or rationale to establish a nuclear power development program in Saudi Arabia. Additionally, the Saudi Electric Company has a plan to diversify fuel and reduce the direct burning of crude oil for electricity generation. This plan involves switching from conventional to nonconventional technologies to reduce greenhouse gas emissions from PPs [34]. The NEDRM did not address the strategic need to reduce greenhouse gas emissions from PPs [7]. Some investigators have studied the effect of controlling $\mathrm{CO}_{2}$ emission from conventional and renewable PPs in Saudi Arabia. However, no specific studies have been conducted to evaluate the effect of $\mathrm{CO}_{2}$ taxation on the relative competency of candidate technologies, including nuclear power in the Saudi Arabia energy system [35-37].

The objective of this study was to determine optimal long-term strategic options for introducing new technologies in Saudi Arabia. These should consider the available options (i.e., traditional fuel, renewables, nuclear). The options should also include nuclear power system options based on the present situation of the Saudi Arabia energy system and the official plan in the NEDRM. In this study, a conceptual model of the Saudi Arabia energy system was developed and illustrated by a systematic diagram. Next, various scenarios were developed which simulate potential national energy systems with multiple nuclear power development options. These scenarios consider the constraints on the cost of the overall energy system cost and other 
expenses (e.g., construction time of PPs). The Saudi Arabian energy system was simulated using the MESSAGE energyplanning tool [38‘39]. Additionally, this study included an analysis of the effect of taxation policy on greenhouse gas emissions from PPs in the Saudi Arabia energy system.

This study is a case study for a country intending to introduce nuclear power (i.e., Saudi Arabia) for optimizing its future national energy system through the use of the MESSAGE tool. This study adopted a new approach for establishing scenarios by assuming possible deployment of a combined nuclear fleet consisting of two different types of NPPs. Furthermore, we applied the G4ECONS tool to calculate and compare the levelized costs for different types of nuclear generation. The levelized costs are not explicitly considered in the levelized Unit Energy Cost (LUEC) calculation incorporated in the objective function of the MESSAGE tool [40-42].

\section{Materials and Methods}

2.1. MESSAGE as an Energy-Planning Tool. Various software tools for energy planning have been developed to evaluate future energy systems, including LEAP, POWERWORLD, WASP, PSSE, VULARAGUA, EMPS, and MESSAGE. The MESSAGE tool was developed by the International Atomic Energy Agency and has been widely used for long-term energy system planning. MESSAGE is based on a dynamic linear programming model to minimize the total system costs and discount all costs occurring at time points later than the base year [43-45].

In this study, the MESSAGE tool was used to evaluate the Saudi Arabia energy system. The MESSAGE tool has advantages due to the following features [39]:

(i) Capability to combine technologies and fuels to construct so-called "energy chains" (see Section 2.3): this capability enables map energy to flow from resource extraction and energy conversion (supply side) to the distribution and provision of energy services (demand side) [38]

(ii) Flexibility to introduce and simulate energy policy and technology choices: these factors may influence future energy demand and supply over time [39]

(iii) Capability to ensure sufficient energy supply for generating technologies and resources based on the specified energy demand: this is accomplished by continuous simulation along the energy chain from supply to demand [45]

(iv) Potential to define and introduce different types of PPs: these types of PPs include NPPs with detailed technical data for an extended time frame (i.e., over 50 years) [43]

2.2. The G4ECONS Tool. The G4ECONS tool was used to generate a more accurate calculation and analysis of the levelized costs of the various generation IV systems. G4ECONS is a Microsoft Excel-based tool that was developed for economic analyses. G4ECONS has four main requirements: simplicity, universality, transparency, and adaptability [40, 42]. Therefore, the G4ECONS tool can evaluate the relationship between construction lead time and levelized costs. In this study, G4ECONS was used to estimate the interest rate duration construction (IDC). It was also used to calculate the Total Capital Investment Cost (TCIC), LUEC, and levelized unit product cost (for nonelectricity applications) of different nuclear energy systems. G4ECONS was used to evaluate the effect of decommissioning costs and radioactive waste management from the nuclear generation processes [46-58].

2.3. Collection of Basic Information and Input Data. A set of data for Saudi Arabia were collected and rearranged for input into the MESSAGE tool to simulate the national energy system. A wide range of national statistical data, technical reports, and other previous studies on the Saudi Arabia energy system were reviewed. Technical and economic data with detailed information about existing and candidate PPs in Saudi Arabia were adopted from official reports and recent studies. This information included capacity, type of fuel, lifetime, efficiency, capacity factor, investment cost, variable or fixed operation, maintenance cost, electric power production, and demand [6 8 ]. Information on the available national resources of crude oil and natural gas was obtained from official statistics issued by the Saudi Arabia government [59].

2.4. Modeling the Saudi Arabian Energy System and Definition of Base Year. A well-organized flow diagram of the energy system is helpful when developing energy-planning studies for a country. The flow diagram shows the energy levels (ranging from resource to demand) and their interconnected chains. It is useful for understanding the whole energy system. However, no specific energy system flow diagram of the Saudi Arabian energy system has not been reported in the public domain literature. This study modeled the energy system of Saudi Arabia by using a systematically conceptualized energy system flow diagram based on the abovementioned information and data collected with the MESSAGE methodology [60]. The national energy system of Saudi Arabia was structured in a supply of energy network (i.e., physical flow model), which included energy resources (i.e., crude oil, natural gas, and their derivatives, and other imported energy resources), primary, secondary, and final energy levels. The simplified Saudi Arabian energy system flow diagram is shown in Figure 1.

2015 was selected to be the base year for the MESSAGE calculation. 2015 was chosen because it was the most recent year with available background information on the economy and energy status of Saudi Arabia. The MESSAGE calculations were performed for 2015 to 2050, with a five-year time step for each calculation and an assumed annual discount rate of $2.1 \%$.

2.4.1. Resource Level. In this study, "resource" is defined as a raw resource such as coal, oil, natural gas in the ground, or biomass in a field [60]. As of 2015, the primary energy system resources in Saudi Arabia were crude oil (63\%) and natural 


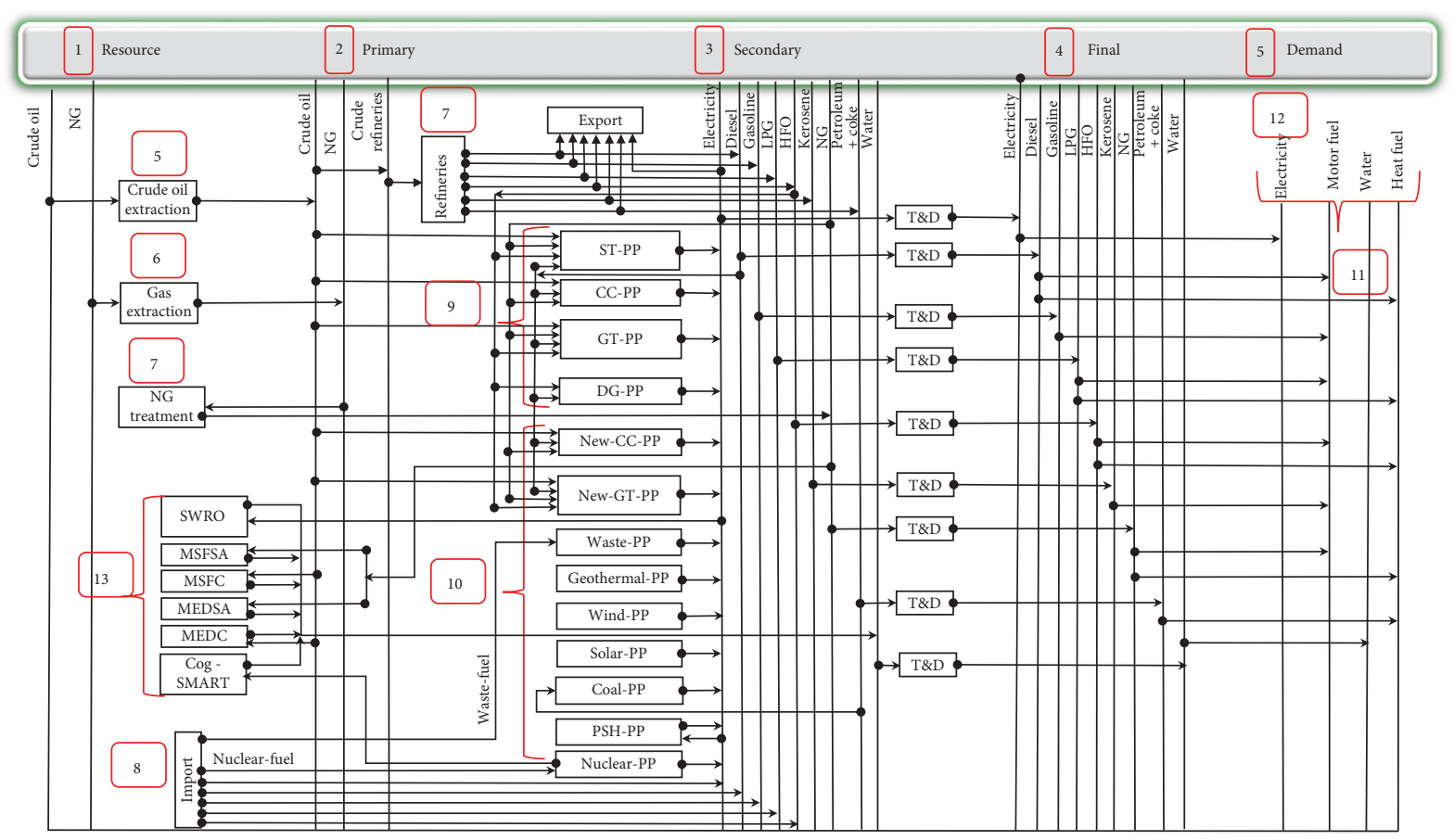

Figure 1: Simplified Saudi Arabian energy system flow diagram including the energy chains, levels, and technologies structured in this study.

gas (37\%). The amount of strategic reserve of crude oil reached 266 billion barrels with a daily production of greater than 10.5 million barrels [61]. The natural gas reserve was reported to be approximately 303.251 billion cubic feet [60]. These resources (i.e., crude oil and natural gas) are transferred to refineries or gas treatment facilities after extraction. Next, these resources are processed to produce the derivatives used in the primary energy level. This type of primary energy level is identified as " 1 " in Figure 1.

2.4.2. Primary Energy Level. In this study, "primary energy" is defined as a raw product at a generation site (e.g., crude oil input to the refinery) [45-60]. Based on this definition, the Saudi Arabian energy system's primary energy level was defined as extracted crude oil and natural gas for transfer to refinery and treatment facilities, respectively. This type of primary energy level is identified as " 7 " in Figure 1. Imported derivatives or fuel (e.g., nuclear fuel for NPPs) and waste from PPs were categorized as the primary energy levels [62]. This type of primary energy level is identified as " 2 " in Figure 1.

2.4.3. Secondary Energy Level. "Secondary energy level" is defined as a finalized product on a generation site (e.g., gasoline or diesel fuel output from the refinery) [59]. Therefore, the Saudi Arabia energy system's secondary energy level was defined as the following energy forms: oil derivatives, including LPG, gasoline, kerosene, diesel, heavy fuel oil (HFO), petroleum coke, and natural gas derivatives, including treated natural gas [61]. The secondary energy level was identified as " 3 " Figure 1 . In this study, the future production of derivatives of crude oil in Saudi Arabia refineries was predicted by assuming the annual average growth rate for the period 2007 to 2015 (i.e., 5.3\% for LPG, $14.2 \%$ for gasoline, $2.3 \%$ for kerosene, $5.7 \%$ for diesel, $18 \%$ for $\mathrm{HFO}$, and $2.1 \%$ for petroleum coke) and the actual production of the 2015 base year [59'62]. The secondary energy level also includes the main electricity transmission lines to four regions (i.e., east, west, center, and south), all existing PPs (identified as "9" in Figure 1), all desalination units (including Cog-SMART, which was identified as "13" in Figure 1), and candidate PPs (identified as "10" in Figure 1).

The imported items (identified as " 8 " in Figure 1 ) include the imported electrical power from the Gulf Cooperation Council (GCC) countries' grid interconnections between the six Arab states of Kuwait, Saudi Arabia, Bahrain, Qatar, UAE, and Oman. The imported power is expected to drive the market in the future. This plan aims to supply both Kuwait and Saudi Arabia with a 1200 MW of power capacity (along with $900 \mathrm{MW}$ for UAE, $750 \mathrm{MW}$ for Qatar, $600 \mathrm{MW}$ for Bahrain, and $400 \mathrm{MW}$ for Oman) [8]. This project was overseen by the board of directors of the GCC Interconnection Authority (GCCIA). Other imported items (e.g., oil fuels), nuclear fuel for the NPPs, and waste from the PPs were also represented in the energy system flow diagram. However, some of the oil derivatives (e.g., asphalt) were not considered in Figure 1 because they do not fit an energy form specified in Table 1.

The average values of the characteristic parameters for the existing PPs available in Saudi Arabia are shown in Table 2. In this study, the characteristic parameters for the assumed candidate PPs (i.e., nonnuclear PPs and NPPs) are listed in Tables 3 and 4 . However, all of the described costs in Table 4 refer to 2020. This study was normalized to the 2015 
TABLE 1: Present and predicted production of crude oil derivatives from refineries in Saudi Arabia (hundred million barrels).

\begin{tabular}{ccccccc}
\hline Year & LPG & Gasoline & Kerosene & Diesel & HFO & $\begin{array}{c}\text { Petroleum } \\
\text { coke }\end{array}$ \\
\hline 2015 & 1675.8 & 17990.1 & 7695.4 & 35147.1 & 16315.6 & 2682.1 \\
2020 & 1764 & 20547.2 & 7873.7 & 37141.7 & 16217.6 & 3795.8 \\
2025 & 1856.9 & 23467.8 & 8056.1 & 39249.5 & 16120.2 & 5371.9 \\
2030 & 1954.7 & 26803.5 & 8242.7 & 41476.9 & 16023.4 & 7602.4 \\
2035 & 2057.6 & 30613.3 & 8433.6 & 43830.8 & 15927.1 & 10759.1 \\
2040 & 2166 & 34964.7 & 8629 & 46318.2 & 15831.5 & 15226.5 \\
2045 & 2280 & 39934.5 & 8828.9 & 48946.8 & 15736.4 & 21548.9 \\
2050 & 2400.1 & 45610.8 & 9033.4 & 51724.5 & 15641.9 & 30496.6 \\
\hline
\end{tabular}

base by assuming that Saudi Arabia and South Korea have the same economic parameters as the US [64-66]. We assumed that the nominal discount rate value from the revised Appendix C of Circular A-94 approximated the current economic factors in 2015 for both APR-1400 and SMART100 reactors during the operation time. We considered the US economic factors, such as the inflation rate and the incremental escalation (i.e., the base of the nuclear projects experience) in our calculation, as shown in Table 10 [64]. We also considered other US economic factors, including inflation rate and incremental escalation (i.e., the base of the nuclear projects experience) in our calculation. The capital cost was set to $1.7 \%$ to represent the general inflation rate per year. Additionally, the incremental escalation rate was set to $3 \%$, and the nominal discount rate was set to $2.1 \%$ [65]. The normalized costs in Table 4 were calculated for all units using the net present value (NPV), and the reference year for cost assessment was set to 2015. The normalized costs were based on the following equation [66]:

$$
\mathrm{NPV}=\frac{\text { Base Cost } \cdot\left(1+I_{\text {inf }}\right)^{n} \cdot\left(1+I_{\text {inc esc }}\right)^{n}}{\left(1+I_{d}\right)^{n}},
$$

where $I_{\text {inf }}$ is the general inflation rate, $I_{\text {ins esc }}$ is the incremental escalated rate, $I_{d}$ is the nominal discount rate, and $n$ is the number of years after the base year.

The characteristic parameter values for the desalination systems representing an integrated nuclear desalination system (i.e., cogeneration (Cog- SMART)) are shown in Table 5 [11].

2.4.4. Final Energy Level. In this study, "final energy" is defined as a finalized product at its consumption point (e.g., gasoline in a car's tank or electricity leaving a socket) [56]. The final energy level of the Saudi Arabia energy system was defined as electricity and other energy forms (e.g., diesel, gasoline, kerosene, HFO, and LPG) produced by the secondary level (e.g., PPs or refineries) and then transferred to the final level (i.e., consumption point) [44]. The final energy level is identified as " 4 " in Figure 1.

2.4.5. Demand Level. In this study, "demand" or "useful energy" in the Saudi Arabia energy system was defined as the final products satisfying the demand for services, such as heating by heat fuel, lighting by electricity, and moving people and freight by transportation. Demand is identified as "5" in Figure 1 [59]. The only electricity demand level was considered in this study was identified as "12" in Figure 1.

In this study, the electricity peak demand (EPD) after the 2015 base year was calculated by adopting the annual growth rate of the EPD for each region assumed in an official report. The EPDs were assumed to be $6 \%, 5 \%, 5 \%$, and $9 \%$ for the East region, West region, Central region, and South region, respectively $[6,8,75,76]$. The forecasted EPDs were further adjusted by considering a feasible future demand reduction of $8 \%$ in Saudi Arabia. Previous studies report future demand reduction due to the possible decrease in electricity consumption from the use of high-efficiency electrical appliances, which have lower losses (e.g., cooling system, water heating, lighting, and smart loads) in Saudi Arabia identified in past studies $[75,76]$.

The total projected EPDs for Saudi Arabia were estimated using an Equation from the manual of the Model for Analysis of Energy Demand (MAED). The total projected EPDs for Saudi Arabia are detailed in Table $6[6,8,77]$. The EPDs projected in this study (i.e., 68.7 GWe in 2020 and 135.5 GWe in 2032) compared well the predictions reported by the World Nuclear Association (i.e., 70 GWe in 2020 and 120 GWe in 2032).

Forecasts in another study estimated that Saudi Arabia's energy demand will grow annually by $8 \%-10 \%$. The peak demand was expected to be 70 GWe in 2020 and reach 120 GWe by 2032, driven partially by the increase in desalination. Desalination represented about $41 \%$ of the other consumption sectors in Saudi Arabia. However, Saudi Arabia was estimated to increase its power generation capacity from 77 GWe in 2014 to 156 GWe by 2040 to meet the projected electricity demand [6, 8-16].

In this study, the capital cost assumptions were demonstrated by previous category classification, including direct construction costs, indirect services costs, preconstruction costs, owner costs, supplementary costs, and financing during construction. These values were summarized in Table 7.

2.5. Main Scenarios with Assumptions. To determine the optimal options for Saudi Arabia to supply its EPD sustainably in the long-term, the following four different energy system scenarios were assumed.

2.5.1. Scenario I (Reference Energy Supply). Scenario I is a "do nothing" scenario, in which all of the existing PPs are assumed to be in operation up to their intended design lifetimes and then subsequently dismantled and out of the grid without either rehabilitation of existing PPs or introduction of any new PPs.

2.5.2. Scenario II (Rehabilitation of Existing PPs). In Scenario II, it was assumed that old PPs would be rehabilitated. The efficiency of the existing PPs would be upgraded once at the end of their design lifetimes as follows: $38 \%$ to $40 \%$ for ST-PP [79], $45 \%$ to $49 \%$ for GT-PP [80], $40 \%$ to $45 \%$ for CC$\mathrm{PP}$, and $25 \%$ to $30 \%$ for DG-PP [81]. 


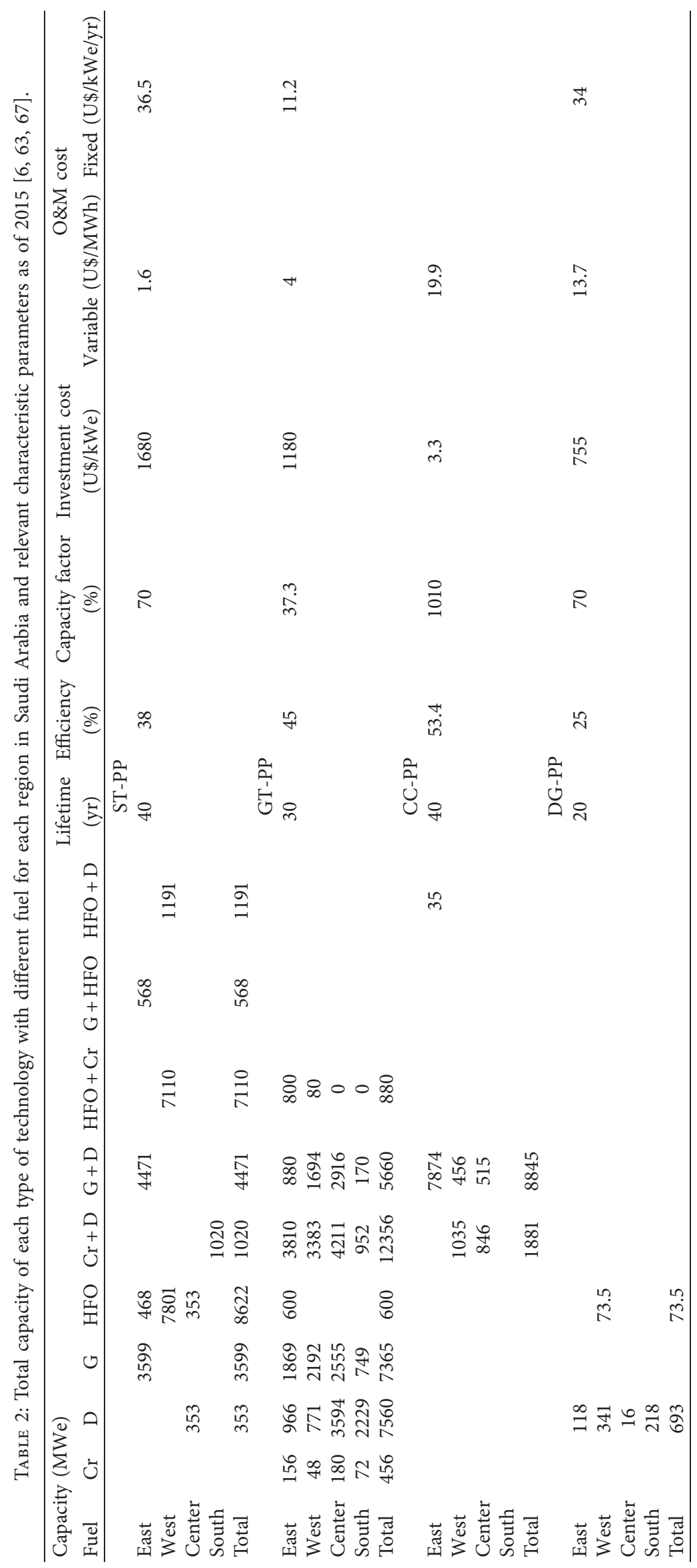


TABLE 3: The characteristic parameters of candidate nonnuclear PPs assumed in this study [67-73] ${ }^{(1)}$.

\begin{tabular}{|c|c|c|c|c|c|c|c|c|}
\hline Power plant & Region & $\begin{array}{c}\text { Construction time } \\
\qquad(\mathrm{yr})\end{array}$ & $\begin{array}{c}\text { Efficiency } \\
(\%)\end{array}$ & $\begin{array}{c}\text { Lifetime } \\
(\mathrm{yr})\end{array}$ & $\begin{array}{c}\text { Capacity } \\
\text { factor } \\
(\%)\end{array}$ & $\begin{array}{l}\text { Capital cost } \\
(\mathrm{U} \$ / \mathrm{kWe})\end{array}$ & $\begin{array}{c}\text { Variable O\&M } \\
\text { cost } \\
(\mathrm{U} \$ / \mathrm{MWh})\end{array}$ & $\begin{array}{c}\text { Fixed O\&M cost } \\
\text { (U\$/kWe/yr) }\end{array}$ \\
\hline A-CC-PP & East, west & 2 & 58 & 35 & 80 & 891 & 0 & 22.3 \\
\hline A-GT-PP & South & 2 & 43 & 35 & 90 & 546 & 0 & 16.4 \\
\hline A-ST-PP & Center, east & 2 & 42 & 25 & 90 & 874 & 0 & 17.5 \\
\hline WT-PP & West & 1 & 27 & 25 & 50 & 6831 & 0.4 & 307.4 \\
\hline WD-PP & West, east & 2 & 50 & 25 & 42 & 1198 & 0.1 & 28.7 \\
\hline GH-PP & South & 2 & 15 & 40 & 65 & 6038 & 0 & 92 \\
\hline \multirow[t]{2}{*}{ SL-PP } & PV center, east, west & 1 & 22 & 30 & 25 & 1021.6 & 0 & 23 \\
\hline & CSP center, east, west & 1 & 40 & 25 & 34 & 630 & 0 & 14.5 \\
\hline CL-PP & East & 2 & 43 & 40 & 80 & 1725 & 0 & 23 \\
\hline PSH-PP & West & 2 & 80 & 50 & 47 & 1408 & 0 & 25 \\
\hline
\end{tabular}

(1) Currency exchange rate of $1 €$ euro $=1.15 \mathrm{U} \$$ is applied based on the conversion assumed in the MESSAGE tool.

TABle 4: The operational parameters of candidate NPPs assumed in this study [33, 48-58].

\begin{tabular}{lcccccccccc}
\hline $\begin{array}{l}\text { Power } \\
\text { plant }\end{array}$ & $\begin{array}{c}\text { Th-P } \\
(\mathrm{MWt})\end{array}$ & $\begin{array}{c}\text { Cn-T } \\
(\mathrm{yr})\end{array}$ & $\begin{array}{c}\text { Th-E } \\
(\%)\end{array}$ & $\begin{array}{c}\mathrm{L}-\mathrm{T} \\
(\mathrm{yr})\end{array}$ & $\begin{array}{c}\text { Ca-F } \\
(\%)\end{array}$ & $\begin{array}{c}\text { FB } \\
(\mathrm{GWtd} / \mathrm{MTHM})\end{array}$ & $\begin{array}{c}\text { SP } \\
(\mathrm{MWt} / \mathrm{MTHM})\end{array}$ & $\begin{array}{c}\text { CC } \\
(\mathrm{U} / \mathrm{kWe})\end{array}$ & $\begin{array}{c}\text { NC } \\
(\#)\end{array}$ & $\begin{array}{c}\text { FOM } \\
(\mathrm{U} \$ / \mathrm{MWh})\end{array}$ \\
\hline $\begin{array}{l}\text { SMART- } \\
100\end{array}$ & 300 & 3 & 33 & 60 & 90 & 40 & 33 & 10000 & 1 \\
APR-1400 & 390000 & 6 & 33 & 60 & 90 & 42.2 & 37.9 & 52.4 \\
\hline
\end{tabular}

Th-P (MWt): thermal power, Cn-T (yr): construction time (yr), Th-E (\%): thermal efficiency (\%), L-T (y): lifetime (yr), Ca-F (\%): capacity factor (\%), FB (GWtd/MTHM): fuel burnup (GWtd/MTIHM), SP (MWt/MTHM): specific power (MWt/MTHM), CC (U\$/kWe): capital cost (U\$/kWe), NC(\#): number of cycles (\#), and FOM (U\$/MWh): fuel, operation, and maintenance cost of the reactor (U\$/MWh).

TABLE 5: The characteristic parameters values of the desalination technologies from $[11-16,74,78]$.

\begin{tabular}{|c|c|c|c|c|c|c|}
\hline \multirow[b]{3}{*}{ Nominal thermal power $\left(\mathrm{MW}_{\mathrm{t}}\right)$ generated } & \multirow{3}{*}{$\frac{\text { Cog-SMART }}{330}$} & \multicolumn{4}{|c|}{ Thermal } & \multirow{3}{*}{$\begin{array}{c}\text { Membrane } \\
\text { SWRO } \\
-\end{array}$} \\
\hline & & \multicolumn{2}{|c|}{ MSF } & \multicolumn{2}{|c|}{ MED } & \\
\hline & & - & - & - & - & \\
\hline Annual plant thermal production $\left(\mathrm{GW}_{\mathrm{th}} / \mathrm{yr}\right)$ & 2370 & MSFSA- & MSFC & MEDSA & MEDC & \\
\hline Installed capacity (million $\mathrm{m}^{3} /$ day) & 0.4 & 1.5 & 2.7 & 1.6 & 0.9 & 2.7 \\
\hline Cap cost (million U\$) & 1000 & 3779.4 & 6803.3 & 2892.1 & 1630.9 & 3.901 .1 \\
\hline Cap cost $\left(\mathrm{U} \$ /\left(\mathrm{m}^{3} \cdot\right.\right.$ day $)$ & 1.27 & 2412.5 & 2412.5 & 1731.1 & 1734.7 & 1385.9 \\
\hline Cap cost $(\mathrm{U} \$ / \mathrm{KWh})$ & 0.1405 & 03 & 05 & 02 & 01 & 09 \\
\hline Opex fix $\left(U \$ /\left(m^{3} \cdot\right.\right.$ day $)$ & 0.25 & 120.6 & 120.6 & 12.5 & 57.2 & 55.4 \\
\hline Opex fix (U\$/KW/yr) & 16.5 & 50.38 & 50.38 & 8.70 & 39.83 & 14.46 \\
\hline Var cost $\left(\mathrm{U} \$ / \mathrm{km}^{3}\right)$ & 0.45 & 0.12 & 0.12 & 01 & 06 & 06 \\
\hline Lifetime $(\mathrm{yr})$ & 60 & 25 & 25 & 25 & 25 & 25 \\
\hline Thermal energy consumption $\left(\mathrm{kWh}_{\mathrm{th}} / \mathrm{m}^{3}\right)$ & - & 85 & 202.5 & 68 & 168 & 4.1 \\
\hline Electrical energy consumption $\left(\mathrm{kWh}_{\mathrm{el}} / \mathrm{m}^{3}\right)$ & - & 2.5 & 2.5 & 1.5 & 1.5 & 4 \\
\hline
\end{tabular}

Cog: cogeneration, MSF: multistage flash, MED: multiple effect distillation, SWRO: seawater reverse osmosis, MSFSA: MSF stand alone, MSFC: MSF cogeneration, MEDSA: MED stand alone, MEDC: MED cogeneration and other: other technologies, including those that use brackish water, Cap cost: capital cost, Opex fix: operation fixed cost, and Var cost: variable cost.

TABLE 6: The projected electricity peak demand of Saudi Arabia predicted in this study (GWe).

\begin{tabular}{lcccccccc}
\hline Year & 2015 & 2020 & 2025 & 2030 & 2035 & 2040 & 2045 & 2050 \\
\hline East & 18.4 & 24.3 & 34.8 & 49.5 & 70.1 & 99 & 139.5 & 196.1 \\
Center & 16.4 & 18.8 & 23.3 & 28.8 & 35.5 & 43.5 & 53.3 \\
West & 16.1 & 17.6 & 20.9 & 24.6 & 28.8 & 33.7 & 39.3 \\
South & 5.8 & 8 & 12 & 18 & 26.6 & 39.4 & 58.1 \\
Total & 56.7 & 68.7 & 91 & 120.9 & 161 & 215.6 & 290.2 & 85.5 \\
\hline
\end{tabular}


TABle 7: Capital cost category estimate for the candidate NPPs assumed in this study [46-58].

\begin{tabular}{|c|c|c|c|c|}
\hline Category & Unit & $\%$ of total & APR-1400 & SMART-100 \\
\hline \multicolumn{5}{|l|}{ Direct construction costs } \\
\hline Equipment & $\mathrm{U} \$ / \mathrm{kW}$ & 15 & 857.1 & 1500 \\
\hline Labor & $\mathrm{U} \$ / \mathrm{kW}$ & 14 & 800 & 1400 \\
\hline Materials & U\$/kW & 4 & 228.6 & 400 \\
\hline Direct construction subtotal & $\mathrm{U} \$ / \mathrm{kW}$ & 33 & 1885.6 & 3300 \\
\hline \multicolumn{5}{|l|}{ Indirect services costs } \\
\hline Off-site engineering and design & $\mathrm{U} \$ / \mathrm{kW}$ & 13 & 742.8 & 1300 \\
\hline On-site project management & $\mathrm{U} \$ / \mathrm{kW}$ & 10 & 571.4 & 1000 \\
\hline Other on- and off-site indirect services & $\mathrm{U} \$ / \mathrm{kW}$ & 14 & 800 & 1400 \\
\hline Indirect services subtotal & $\mathrm{U} \$ / \mathrm{kW}$ & 37 & 2114.2 & 3700 \\
\hline Direct and indirect construction subtotal & $\mathrm{U} \$ / \mathrm{kW}$ & 70 & 3999.8 & 7000 \\
\hline Preconstruction costs & & 2 & 114.3 & 200 \\
\hline Owner's costs & & 10 & 571.4 & 1000 \\
\hline Supplementary costs & & 1 & 57.1 & 100 \\
\hline Financing during construction & & 17 & 971.4 & 1700 \\
\hline Total capital costs & $\mathrm{U} \$ / \mathrm{kW}$ & & 5714 & 10000 \\
\hline
\end{tabular}

2.5.3. Scenario III (Introduction of New Energy Technologies including NPPs). Some of the existing PPs, such as ST-PPs, CC-PPs, and DG-PPs, have been operated for longer than 30 years. The aging of the existing PPs may cause a risk to the sustainability of the energy system of Saudi Arabia in the future. To cope with the potential challenge against the sustainable electricity supply, Saudi Arabia has planned to introduce new technologies, including NPPs, in the future [6-9]. In 2013, Saudi Arabia selected three candidate sites to construct NPPs represented by Jubail on the Arabian Gulf (in East region), Tabuk (in West region) close to the Red Sea, and Jizan on the Red Sea (in South region) [9]. Furthermore, Saudi Arabia has tremendous wind and sun, and these technologies are considered among the best in the world [69-75]. Nevertheless, Saudi WD-PP and SL-PP prices will be at the low end of the global price range. Some studies reported by WNA, REI, and WNISR provide a potential decline of energy prices from renewals, such as wind and solar, which may improve the competitiveness of such technologies in the energy mix. Due to the limitation of availability of specific discounted cost and the technology development of renewables and reproduction of PPs in the future, the reported values in existing studies were assumed in this study [80-82].

Furthermore, the locations of other candidate technologies have been assumed based upon available energy resources therein. WD-PP is assumed to be introduced in West and East regions, and SL-PP in West, East, and Center regions, reflecting the abundance of wind resources and solar radiation [21] and GH-PP in South region considering the availability of geothermal resources therein [19]. PSH-PP was assumed to be adopted in the West region due to the potential of pumped storage hydro to be built in this region [74]. WT-PP is also assumed to be adopted in the West region due to the availability of waste fuel either from industrial regions or from agricultural bio-waste materials in the West region [84]. CL-PP is assumed to be in the East region due to coal fuel will be imported through the Persian Gulf seaport, and it is better to reduce the coal transportation cost [37]; A-CC-PP is to be in East and West regions to energize the local industrial sector [86], whereas A-GT-PP being assumed to be in South region as shown in Table 3 $[85,87]$.

There are two families of desalination technologies, such as thermal technology and membrane technology. However, in this study, three desalination units are assumed based on General Electric (GE) suggests that Saudi Arabia requires 300000 barrels of oil per day for the desalination plants on the country's eastern and western coasts with two types of seawater desalination technologies, such as Seawater Reverse Osmosis (SWRO) as membrane technology, while multistage flash (MSF) and multiple effect distillation (MED) as thermal technology as shown in Table 5 [11].

To implement the NEDRM, Saudi Arabia has signed various bilateral cooperation agreements with several nuclear vendor countries. Recently, five countries such as China, France, Korea, Russia, and the USA who submitted letters of intent were designated as preferred bidders for its first NPP project [82]. All of the above five countries have experience constructing large capacity commercial NPPs, such as CNP-1000, P4 REP 1300, OPR-1000, APR-1400, VVER V-491, and WH 4LP (DRYAMB) [83].

The Saudi Arabian government has signed a few agreements with other countries for the development of small-capacity nuclear reactors, including CAREM-25 (27 MWe) of Argentine and SMART-100 (100 MWe) of Korea [9]. More specifically, KEPCO, which has been shortlisted to bid on nuclear power projects in Saudi Arabia, has an experience in constructing and operating large capacity NPPs such as APR-1400 and OPR-1000 [82]. Furthermore, Korea has signed an agreement with the KA-CARE to assess the potential for building at least two small size reactors such as SMART-100 developed by KAERI [9].

Therefore, both large and small NPPs (i.e., APR-1400 and SMART-100) from Korea have been considered as candidate nuclear power reactors in this study. With a view of observing differences in various nuclear power development options possibly introduced into Saudi Arabia, Scenario III was further divided into four subscenarios: 
$>$ Subscenario III-1: introduction of new energy technologies, including a set of APR-1400 only for nuclear power

$>$ Subscenario III-2: introduction of new energy technologies, including a set of SMART-100 only for nuclear power

$>$ Subscenario III-3: introduction of new energy technologies, including a combination of APR-1400 and SMART-100 for nuclear power

It is noted that NPPs are assumed to be excluded from the region "Center" due to the limited availability of surface water resources for reactor cooling in the area compared to the other three regions [48-58].

2.5.4. Scenario IV (Consideration of Carbon Dioxide Emission). It was reported that Saudi Arabia's government showed an interest in applying taxes to carbon dioxide $\left(\mathrm{CO}_{2}\right)$ emission from PPs, though the time for enforcement has not been specified [83]. Subscenarios III-1 to III-3 were expanded to Subscenarios IV-1 to IV-3 by applying an additional constraint of the greenhouse gas emission cost into the MESSAGE tool to compare the relative impact of $\mathrm{CO}_{2}$ taxation to alternative nuclear energy development programs.

In this study, we assumed that the taxation for $\mathrm{CO}_{2}$ emission results in when all types of new candidate PPs were predicted to be introduced to Saudi Arabia (see Section 3.3). As such, operators of PPs should pay $\mathrm{CO}_{2}$ emission tax for the electricity produced thereafter, which may affect any type of technology's economic feasibility depending upon the $\mathrm{CO}_{2}$ emission rate from a specific type of PP. The $\mathrm{CO}_{2}$ emission tax for technology can be calculated by the following equation [88]:

$$
T_{c, k}=\mathrm{EF}_{k} \cdot C_{\text {carbon }},
$$

where $T_{C, k}$ is the $\mathrm{CO}_{2}$ emission tax for technology $k(\mathrm{U} \$ /$ $\mathrm{MWh}$ ), $\mathrm{EF}_{k}$ is the emission factor for technology $k$ (ton of $\left.\mathrm{CO}_{2} / \mathrm{MWh}\right)$, and carbon is the carbon cost $\left(\mathrm{U} \$ /\right.$ ton of $\left.\mathrm{CO}_{2}\right)$ for which the average value of forecasted carbon cost in 2030, $37.5 \mathrm{U} \$ /$ ton of emitted $\mathrm{CO}_{2}$, was assumed for simplification in this study [88-92].

2.6. Levelized Unit Energy Cost. A LUEC was calculated by the G4-ECONS tool for each possible option in the nuclear power fleet (i.e., APR-1400, SMART-100, or a combination of APR-1400 and SMART-100). The LUEC was compared to the results from the MESSAGE simulation. This was performed to verify the results from the MESSAGE tool, which provides an optimal option by minimizing a complicated objective function. In this study, a LUEC of a type of nuclear reactor, $R$, for the whole lifetime was discounted to the 2015 base year and was calculated using (2). In (2), the NPP was assumed to be constructed at the initial time of the project, and the interest during construction was taken into account. The interest during construction (IDC) with nominal discount rates for the capital cost was $2.1 \%$ and $2.5 \%$ for the decontamination and decommissioning (D\&D), respectively, using the following equation [41-58]:

$$
\operatorname{LUEC}_{R}\left(\frac{U}{M W h}\right)=\frac{C_{\mathrm{AC}}+C_{O \& M}+C_{F}+C_{D \& D}}{8760 \cdot P_{\text {net }} \cdot L_{F}},
$$

where $C_{\mathrm{AC}}$ is the annual capital repayment cost, $C_{\mathrm{O} \& \mathrm{M}}$ is the annual operation and maintenance cost, $C_{\mathrm{F}}$ is the annual fuel cost, $C_{\mathrm{D} \& \mathrm{D}}$ is the annual decontamination and decommissioning cost sinking fund contribution, $P_{\text {net }}$ is the net electrical capacity (MWe) or the total useful energy for a cogeneration plant, including the thermal energy expressed in MWe, and $L_{F}$ is the load factor:

$$
\mathrm{IDC}=\left[\left(\frac{m}{2}\right) \cdot i t\right]+\left[\left(\frac{m^{2}}{6}\right) \cdot i t^{2}\right],
$$

where IDC is the interest accrued during construction, $m$ is the monthly interest rate, and it is the number of months to construct.

2.7. Overall Approach and Procedure of This Study. The major steps taken in this study were (i) data collection, (ii) preparation of input data based on the protocol of MESSAGE tool, (iii) establishment of long-term electric power development scenarios encompassing a variety of possible options in Saudi Arabia, (iv) simulation with the MESSAGE tool, (v) analysis of the results from the MESSAGE tool combined with a manual calculation of the LUEC, and (vi) derivation of the main findings and insights. The overall approach and procedure employed in this study are depicted in Figure 2.

\section{Results and Discussion}

Scenarios I, II, III (III-1, III-2, and III-3), and IV were simulated using the MESSAGE tool. The simulations included relevant assumptions and input parameters detailed in Tables 1 to 7 . These simulations were performed to formulate an optimal long-term energy supply strategy, which could meet the electricity demand of Saudi Arabia from 2015 to 2050 .

3.1. Scenario I (Reference Energy Supply). Scenario I was simulated by the MESSAGE tool. The calculated optimal electricity capacity (vertical bar) of each technology and the peak demand (pointed solid line) for every five years starting in 2015 are shown in Figure 3. These results indicated that the electricity shortage would begin to occur in 2025 and continue to the end of the simulation (i.e., 2050). The electricity shortage rate was defined as the electricity gap (i.e., the electricity demand and the actual electricity supply divided by the electricity demand) [94]. The electricity shortage rate was estimated as a percentage. The electricity shortage rate started at $27.1 \%$ in 2025 and increased to $96.2 \%$ in 2050, as shown in Figure 4. The total installed capacity of 73.3 GWe in 2015 is predicted to decrease to 15.1 GWe at the end of 2050. The decrease in the total installed capacity was due to the gradual retirement of existing PPs, which were 


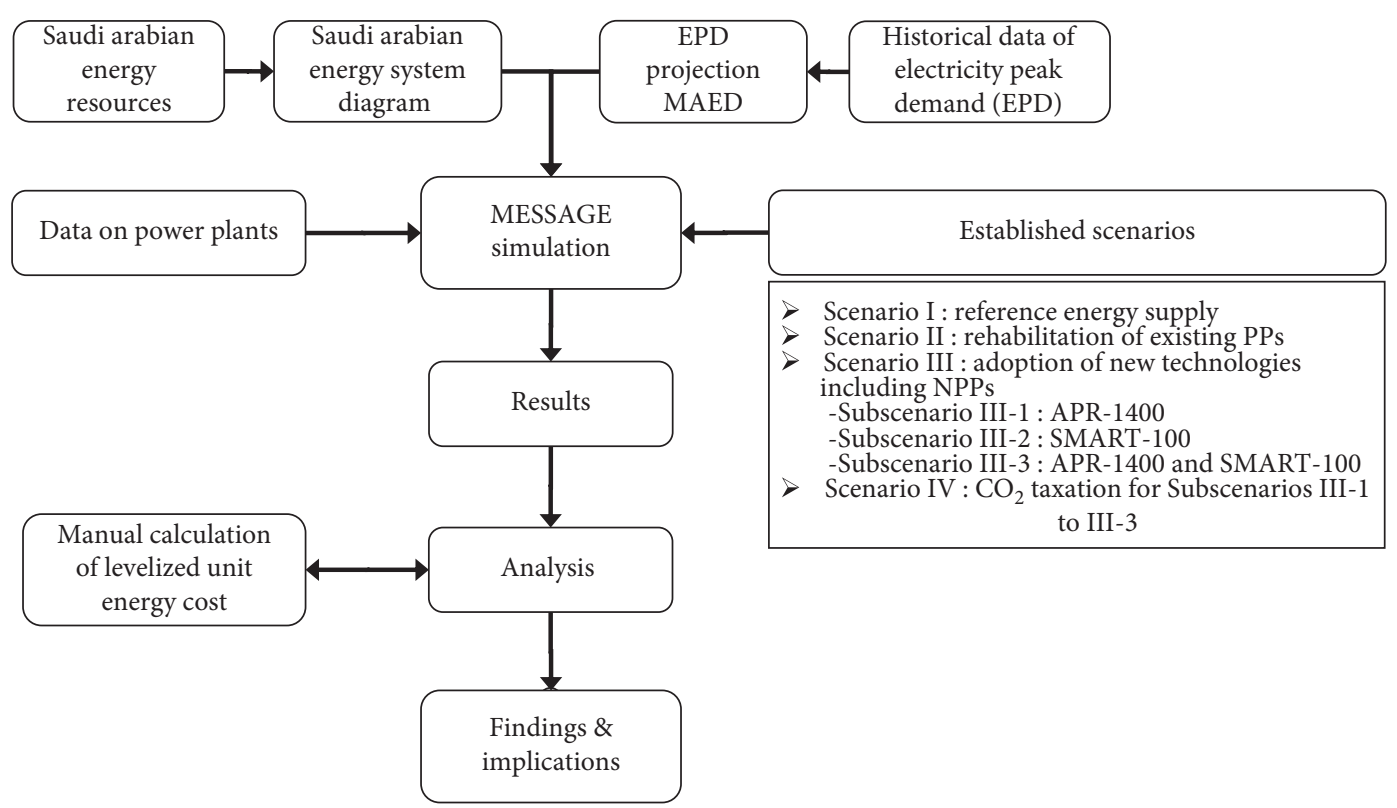

FIgURE 2: Overall approach and procedure for long-term electric power strategy of Saudi Arabia adopted in this study.

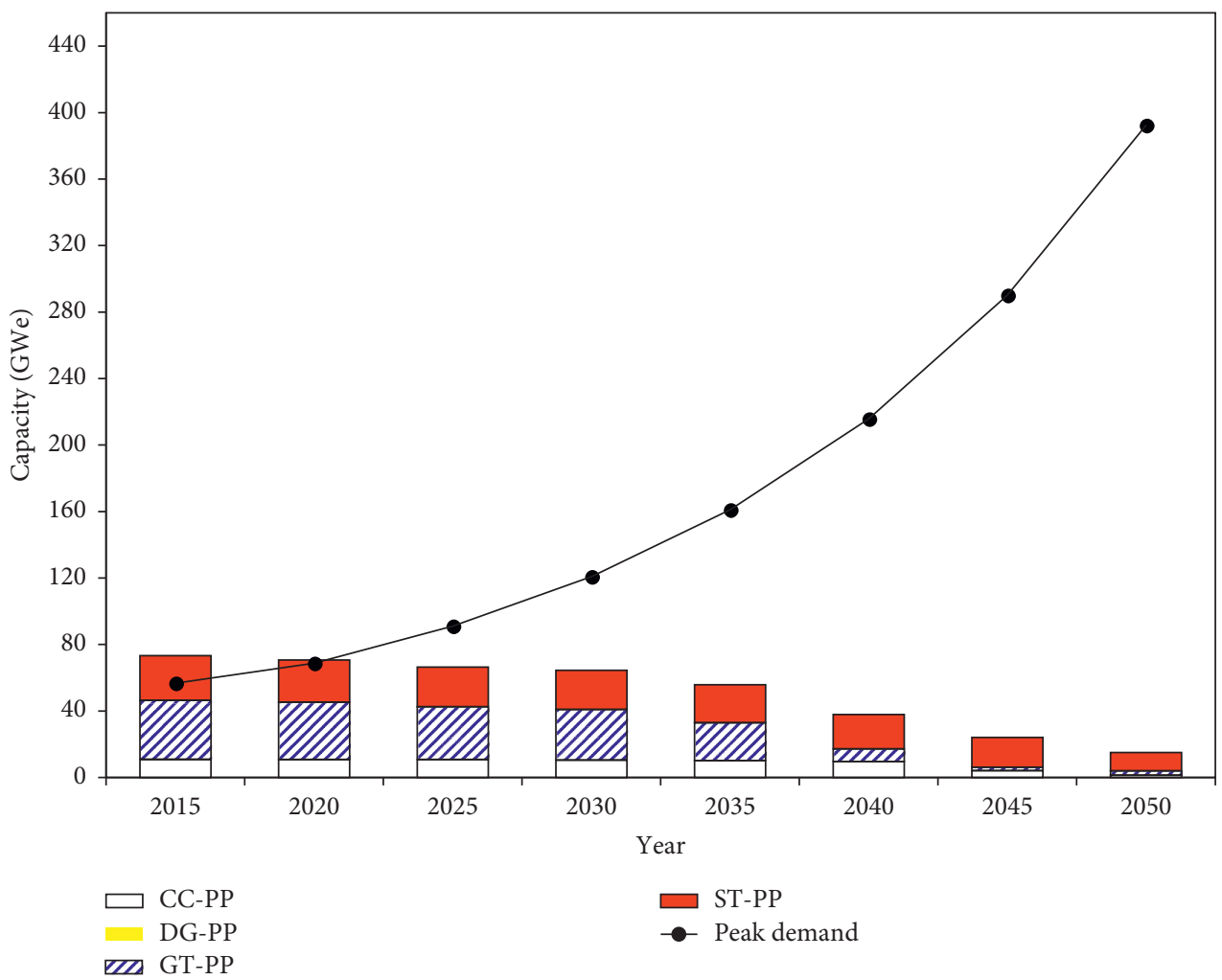

FIgURE 3: Simulation results from MESSAGE tool for Scenario I.

assumed not to be refurbished in Scenario I (see Section 2.4.1). Scenario I was determined not to be a sustainable long-term energy option for Saudi Arabia.

Moreover, Scenario I predicted that gas turbine (GT) PPs would be the major energy technology in Saudi Arabia until 2035. Steam turbine (ST) PPs became the majority thereafter, and diesel generator (DG) PPs showed the smallest share of the capacity throughout the timeframe. This finding was attributed to more GT-PP units reaching the design lifetime earlier than the ST-PPs from 2015 to 2035. The highest share of the GT-PPs was attributed to the highest number of available GT-PPs (i.e., 653 units as of 


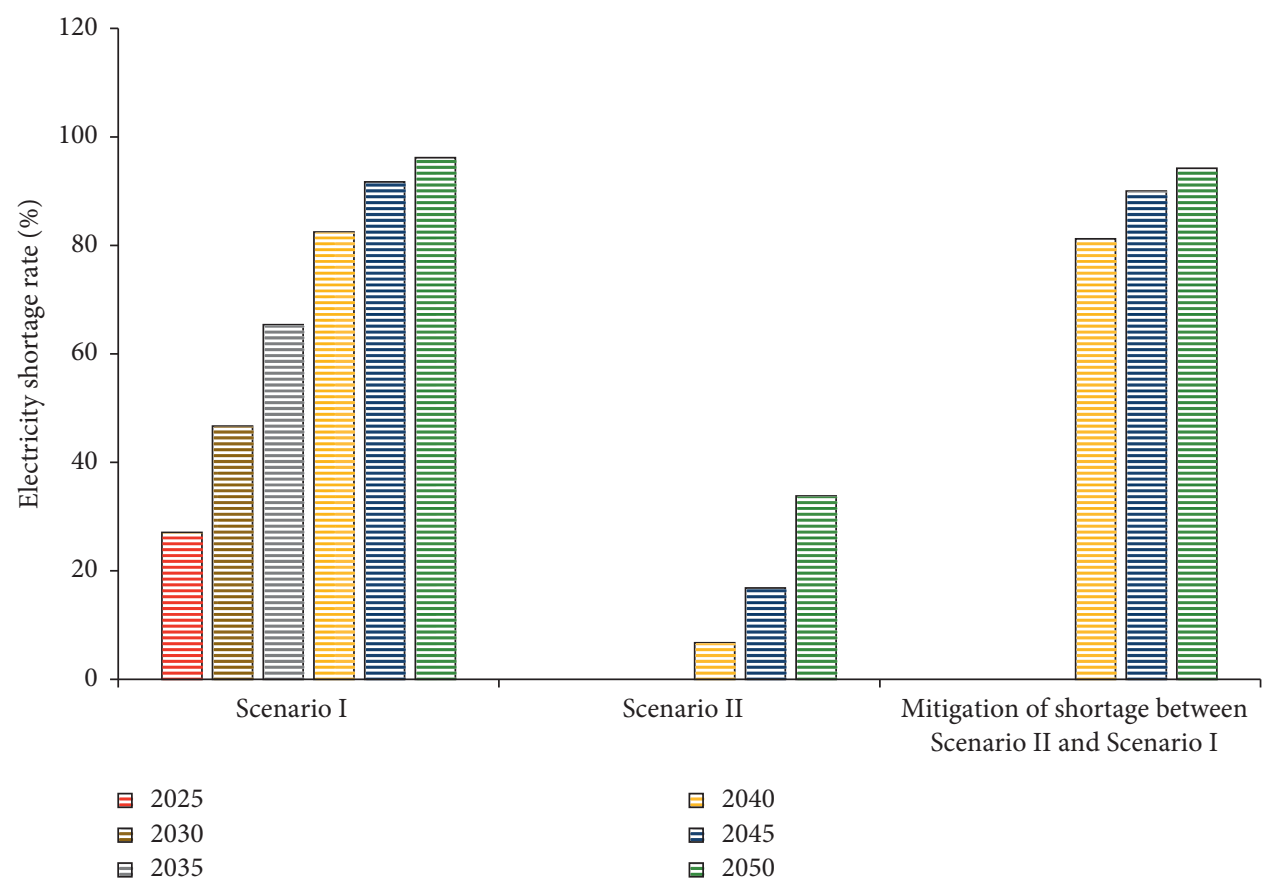

FIgURE 4: Increase in electricity shortage rate and mitigation between Scenarios I and II.

2015) among the total number of existing PPs (i.e., 947 units as of 2015) [5]. The lowest share of DG-PPs was attributed to the comparatively high fixed and variable operation and maintenance costs of DG-PPs compared to the other existing technologies, as shown in Table 2.

\subsection{Scenario II (Rehabilitation of Existing PPS). Figure 5} shows the MESSAGE tool calculation results from Scenario II. Scenario II assumed that the existing PPs were maintained and upgraded to higher efficiency and continued to operate until they reached the original design lifetime (see Section 2.4.2). The installed electricity capacity as of 2050 (i.e., the end of the timeframe of this study) for Scenario II was predicted to reach the maximum 244.6 GWe, whereas a much smaller capacity of 15 GWe was predicted in Scenario I.

The future electricity shortage predicted in Scenario I was solved and/or mitigated to some extent in Scenario II. Scenario II predicted that the estimated EPD could be covered until 2035, as shown in Figure 5. For Scenario I, the electricity shortage was expected to begin in 2020, as shown in Figure 3. In Scenario II, the electricity shortage rate was estimated to be $6.8 \%$ in 2040 and reach $33.8 \%$ by the end of 2050, as shown in Figure 4. Thus, Scenario II showed a reduction in the shortage rate (i.e., mitigated) of $81.2 \%, 90 \%$, and $94.2 \%$ for 2040, 2045, and 2050, respectively, compared to Scenario I.

This study calculated 371 units of PPs (262 units of GTPPs, 59 units of ST- PPs, 43 units of DG-PPs, and 7 units of the combined cycle (CC) PPs would be rehabilitated and upgraded during the timeframe of this study) [6]. The incremental capacity of Scenario II incremental capacity is compared to the incremental capacity of Scenario I in
Figure 6. It was predicted that both GT-PPs and ST-PPs would be two major technologies, and the capacity of the STPPs would increase continuously within the timeframe of this study. As shown in Figure 5, the capacity of the GT-PPs would be higher than other available technologies from 2015 to 2045 and then decrease to the capacity of the ST-PPs. This indicated that GT-PP was the major existing technology in 2015. The number of GT-PP units needing rehabilitation by 2050 (i.e., 262 units) is higher than any other types of PPs considered in this study. Moreover, the highest share of the ST-PPs in 2050 was attributed to the longer lifetime of STPPs compared to the lifetime of GT-PPs (see Table 3).

3.3. Scenario III (Introduction of New Energy Technologies, including NPPs). The MESSAGE tool calculation results for the three Subscenarios III-1, III-2, and III-3 (see Section 2.4.3) are discussed in this section.

3.3.1. Subscenario III-1 (Introduction of New Energy Technologies including APR-1400 as the Only Type of Nuclear Power Reactor). In this subscenario, the following nonnuclear new technologies were introduced starting in 2020: coal (CL) PP, geothermal (GH) PP, waste (WT) PP, solar (SL) PP, wind (WD) PP, pump storage hydro (PSH) PP, advanced combined cycle (A-CC) PP, advanced gas turbine (A-GT) PP, and advanced steam (A-ST) PP. Nuclear power (i.e., APR-1400 in this subscenario) was assumed to be available as a candidate technology starting in 2030.

The calculation results from Subscenario III-1 are shown in Figure 7. In Subscenario III-1, the electricity shortage predicted in Scenarios I and II were resolved by adopting new technologies. 


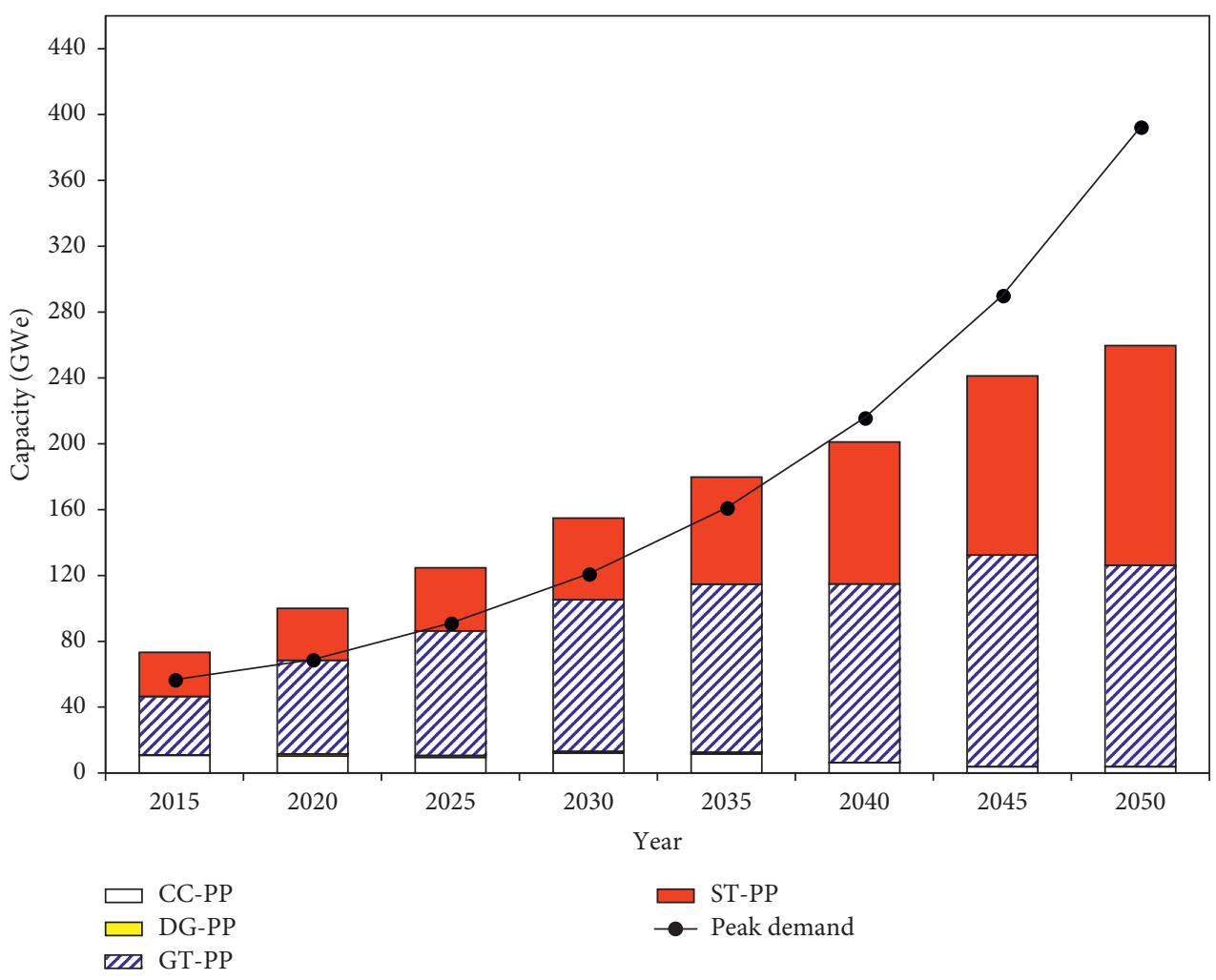

FIgURe 5: Simulation results from MESSAGE tool for Scenario II.

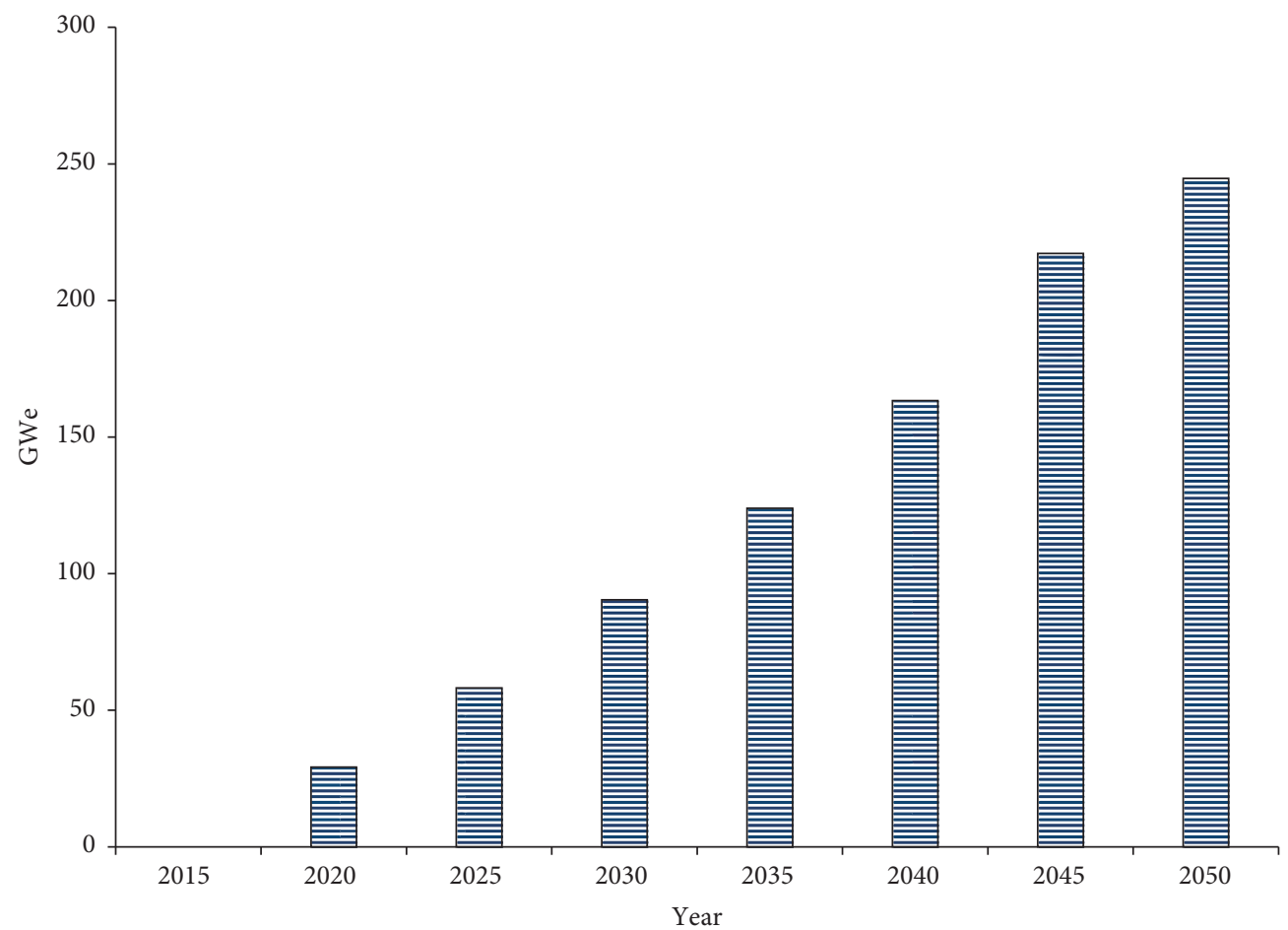

Figure 6: Increments from Scenario II compared to the calculated capacities from Scenario I. 


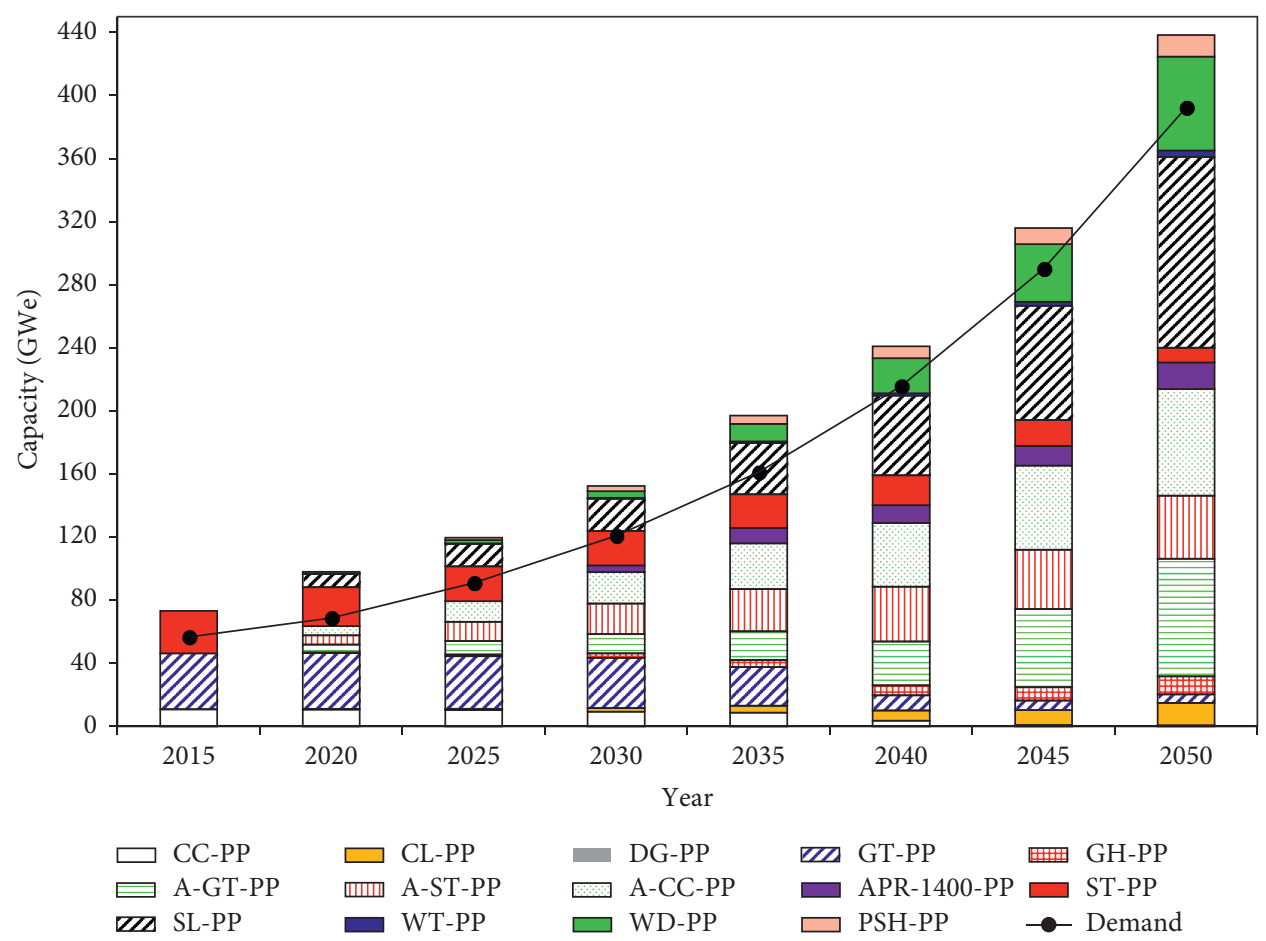

FIgUre 7: Simulation results from MESSAGE tool for Subscenario III-1.

The share of new technologies was forecasted to increase gradually. SL-PP, A-GT-PP, A-CC-PP, WD-PP, and A-ST$\mathrm{PP}$ were predicted to be the top five major technologies in the future energy system of Saudi Arabia. In Subscenario III1, the first NPP unit (i.e., APR-1400) would be introduced around 2030. Its capacity and share would increase from 4.2GWe and $2.8 \%$ in 2030 to $16.8 \mathrm{GWe}$ and $3.8 \%$ in 2050 , as shown in Figure 8. Moreover, nuclear power would be the sixth-largest capacity by the end of the study, as shown in Figure 9. The share of two conventional technologies (i.e., CC-PP and DG-PP) was predicted to decrease throughout this timeframe of the study.

3.3.2. Subscenario III-2 (New Energy Technologies including SMART-100 as the Only Type of Nuclear Power). In Subscenario III-2, the nuclear power (i.e., SMART-100) would contribute a capacity of $0.8 \mathrm{GWe}$ and $0.5 \%$ share in 2030 and reach $6.2 \mathrm{GWe}$ and $1.4 \%$ share by 2050, as shown in Figures 10 and 11. In Subscenario III-2, the SMART-100 reactor ranked eleventh in 2050 as shown in Figure 12 in Subscenario III-2.

The reduced competitiveness of the SMART-100 reactor over the other candidate technologies in Subscenario III-2 compared to Subscenario III-1 was attributed to the high capital cost of the SMART-100 reactor compared to the APR-1400 reactor. The uncertainties and implications of the high capital cost of the SMART-100 reactor are detailed in Table 4 and were thoroughly reviewed and discussed in Section 3.3.4. Moreover, the water desalinated by a CogSMART-100 would be able to cover $123.7 \mathrm{Mm}^{3}$. This is approximately $4 \%$ of the desalinated water demand per unit. All of the Cog-SMART-100 units would be able to cover $9151.8 \mathrm{Mm}^{3}$, which is approximately $80 \%$ of the amount of desalinated water demand by 2050, as shown in Figures 13 and 14 .

3.3.3. Subscenario III-3 (New Energy Technologies including a Combination of APR-1400 and SMART-100 as the Nuclear Power Reactors). The calculation results from Subscenario III-3 are shown in Figure 15. In Subscenario III-3, the combined nuclear fleet of APR-1400 and SMART-100 reactors was assumed to be available starting in 2030. The highest capacity and share of nuclear power as of 2050 was predicted for Subscenario III-3 compared to Subscenario III1 and Subscenario III-2, as shown in Figure 15.

Afterward, the relative capacity and share of the combined nuclear fleet increased continuously to ranking sixth with an installed capacity of 18.9 GWe and a $4.3 \%$ share by the end of 2050, as shown in Figures 16 and 17.

The share of two conventional technologies (i.e., CC-PP and DG-PP) was predicted to decrease throughout the timeframe of the study (i.e., 13th and 14th ranked). The majority of the nuclear capacity was supplied by the large NPPs (i.e., APR-1400). The total capacity contribution of the APR-1400 reactor in the combined nuclear fleet was calculated as $2.6 \%$ and $4.2 \%$ for 2030 and 2050, respectively. The total capacity contribution of the SMART-100 reactor in the combined nuclear fleet was calculated as $0.19 \%$ and $0.16 \%$ for 2030 and 2050 , respectively.

3.3.4. Further Discussions on the Relative Competitiveness of Nuclear Power in Subscenarios III-1 to III-3. The installed capacity of the nuclear power in the Saudi Arabian energy system from 2025 to 2050 calculated for Subscenarios III-1, 


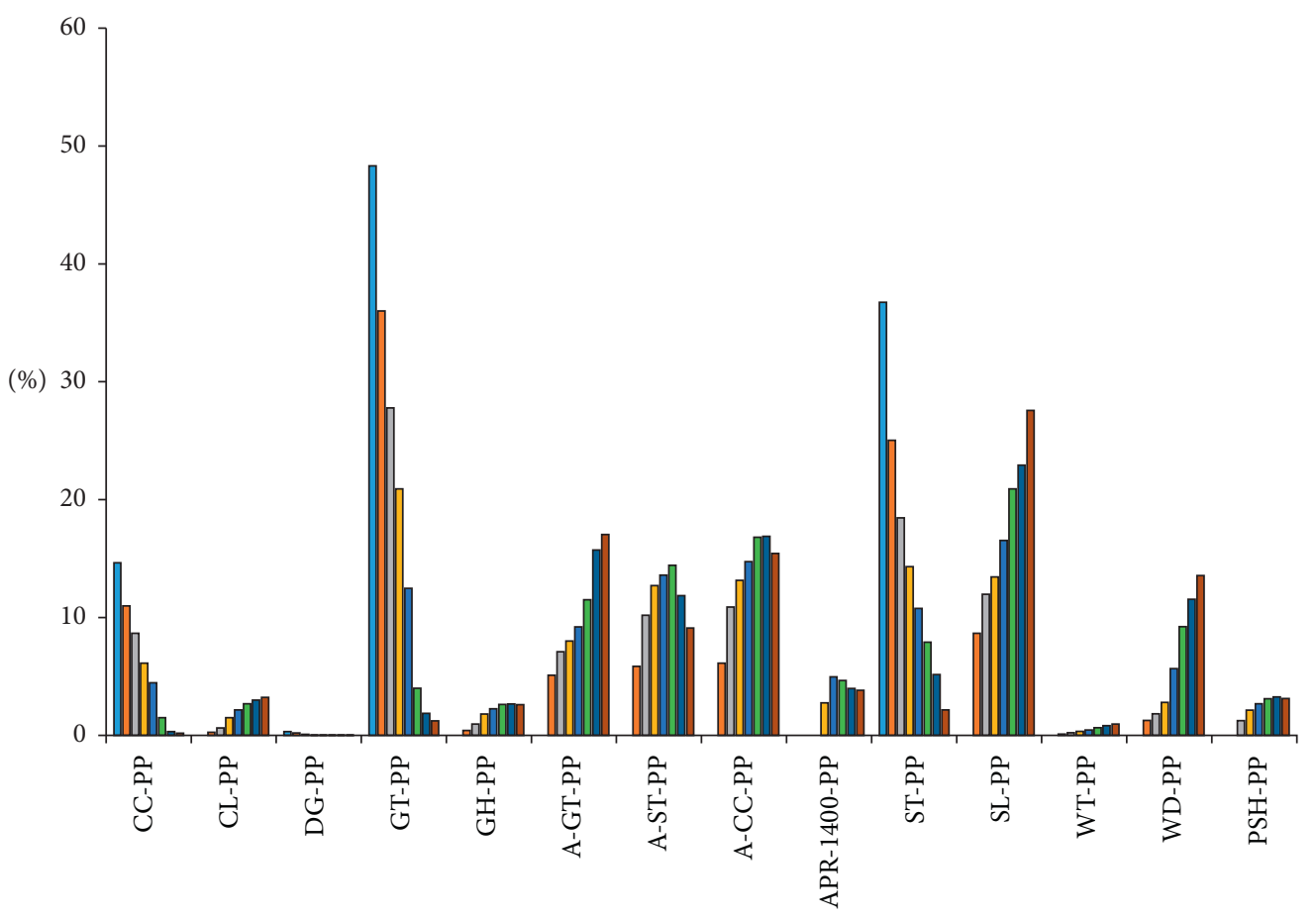
$\square 2015$
$\square 2030$
๑ 2045
$\square 2020$
ㅁ 2035
ธ 2050

FIGURE 8: Share of power plant technologies for Subscenario III-1.

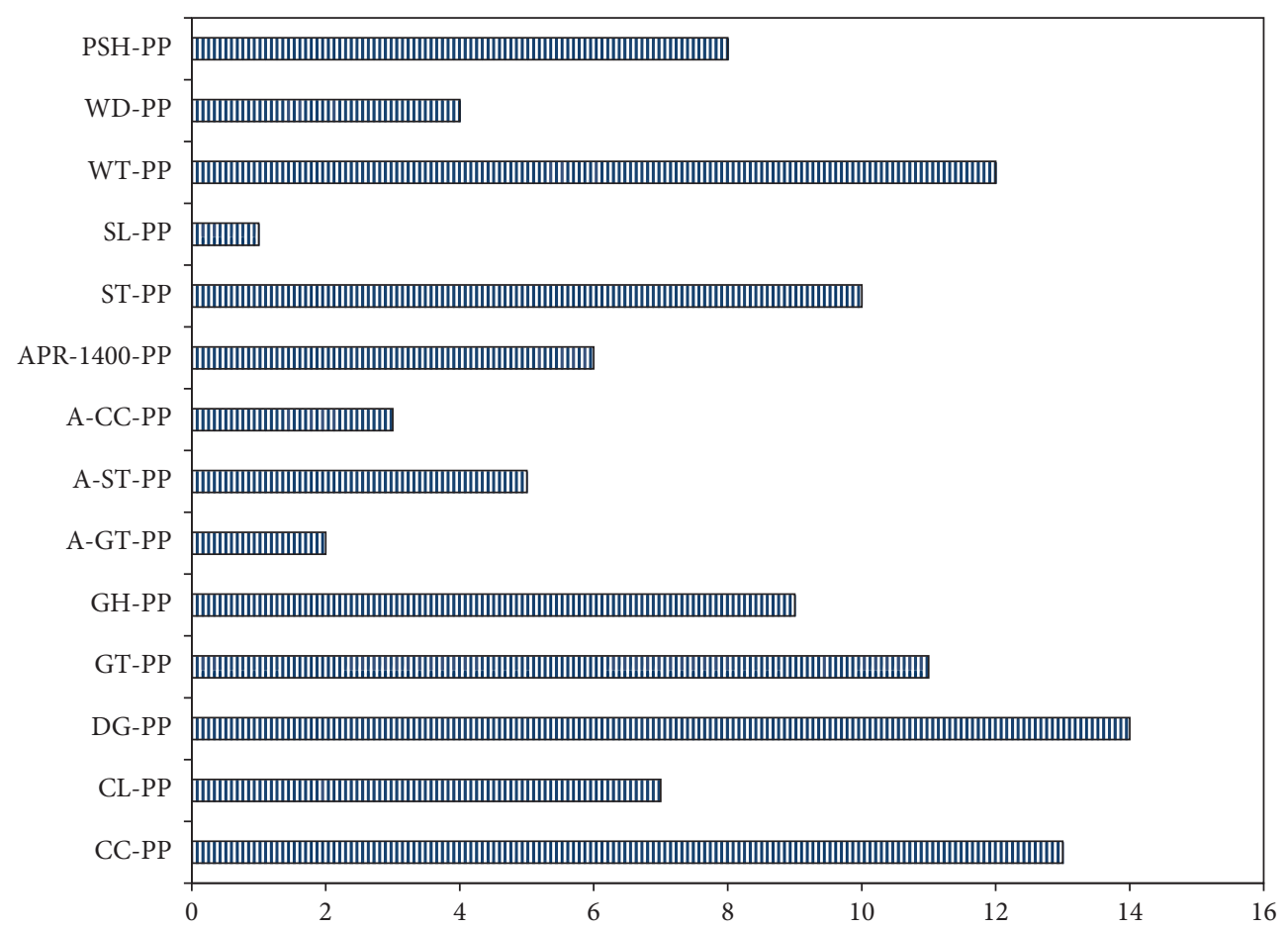

FIgURE 9: Ranking of power plant technologies by 2050 for Subscenario III-1.

III-2, and III-3 (see Figures 7 to 15 by the MESSAGE tool) were rearranged, as shown in Figure 18. The capacity of the combined nuclear fleet of the APR-1400 reactor and the
SMART-100 reactor (Subscenario III-3) was the highest, followed by the APR-1400 reactor (Subscenario III-1) and the SMART-100 reactor (Subscenario III-2). By the end of 


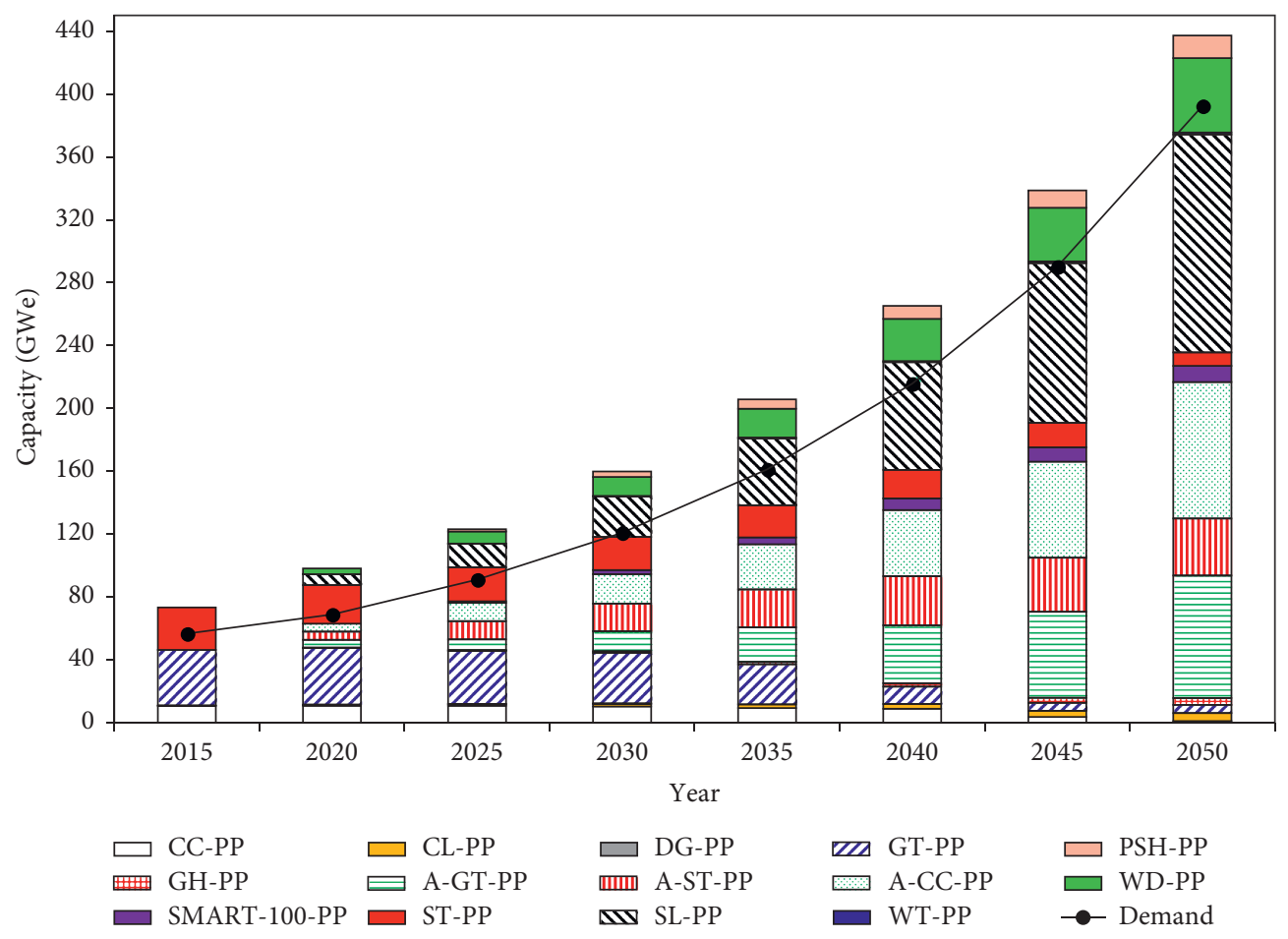

Figure 10: Simulation result from MESSAGE tool for Subscenario III-2.

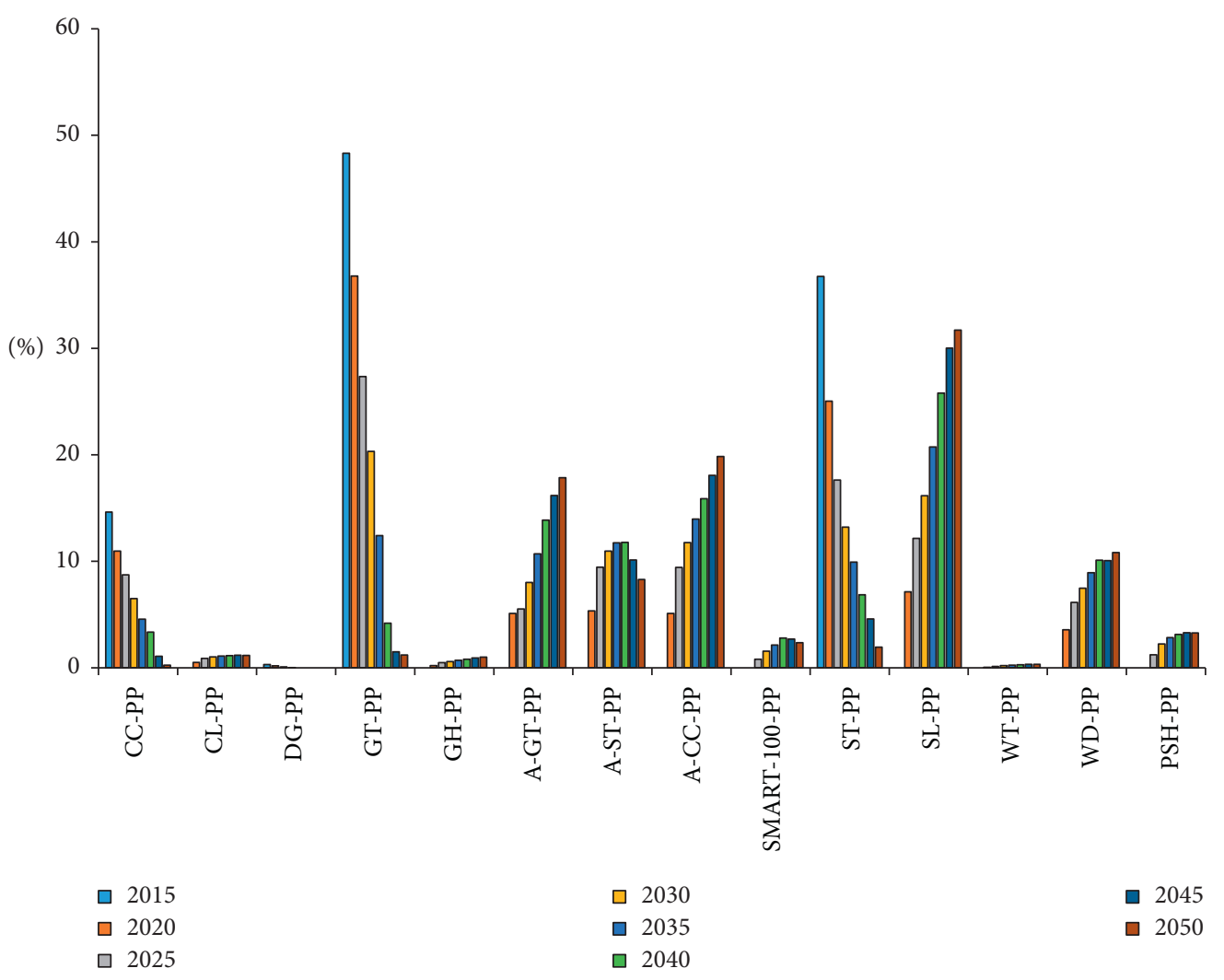

Figure 11: Share of power plant technologies for Subscenario III-2. 


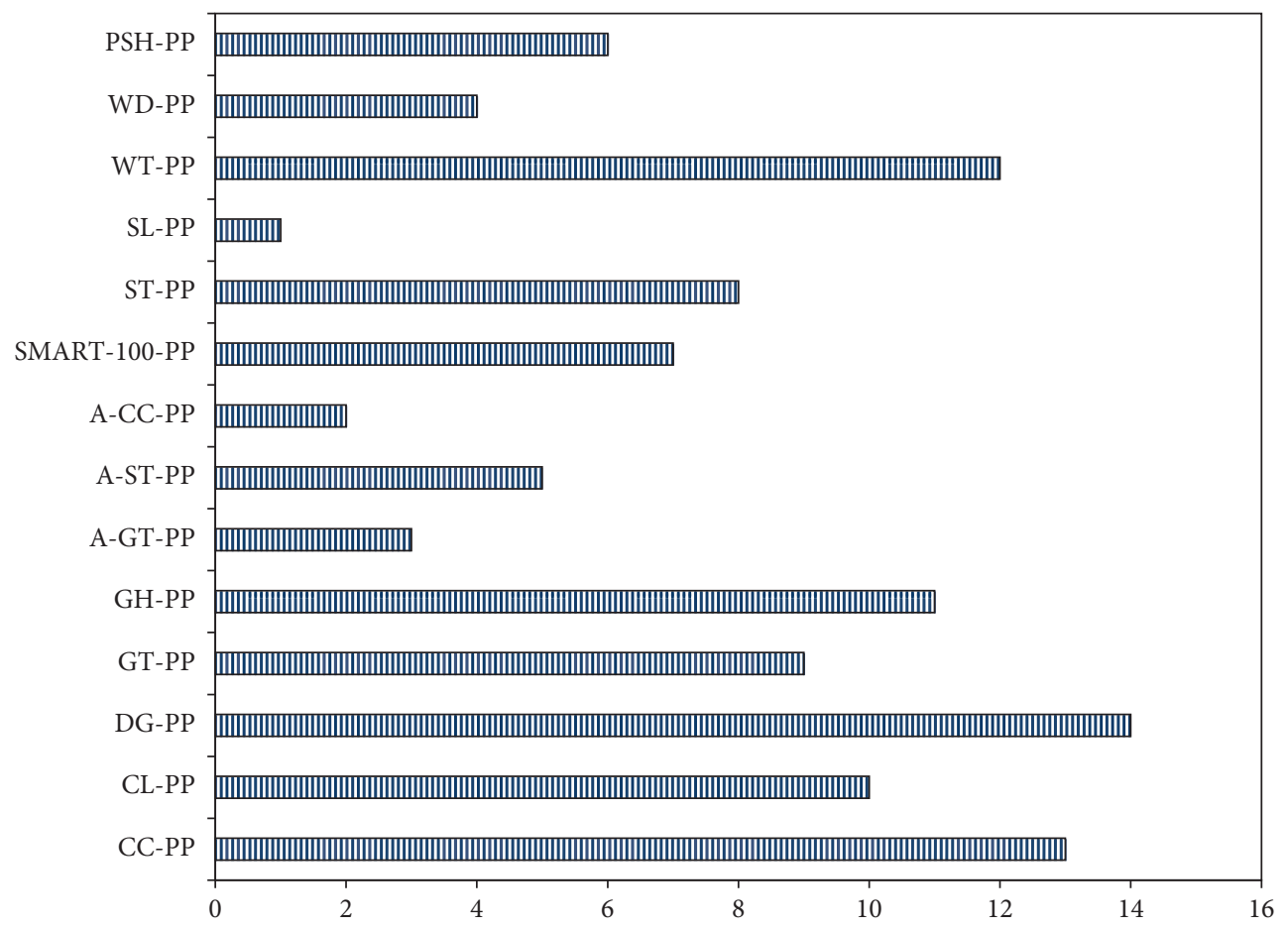

FIgURE 12: Ranking of power plant technologies by 2050 for Subscenario III-2.

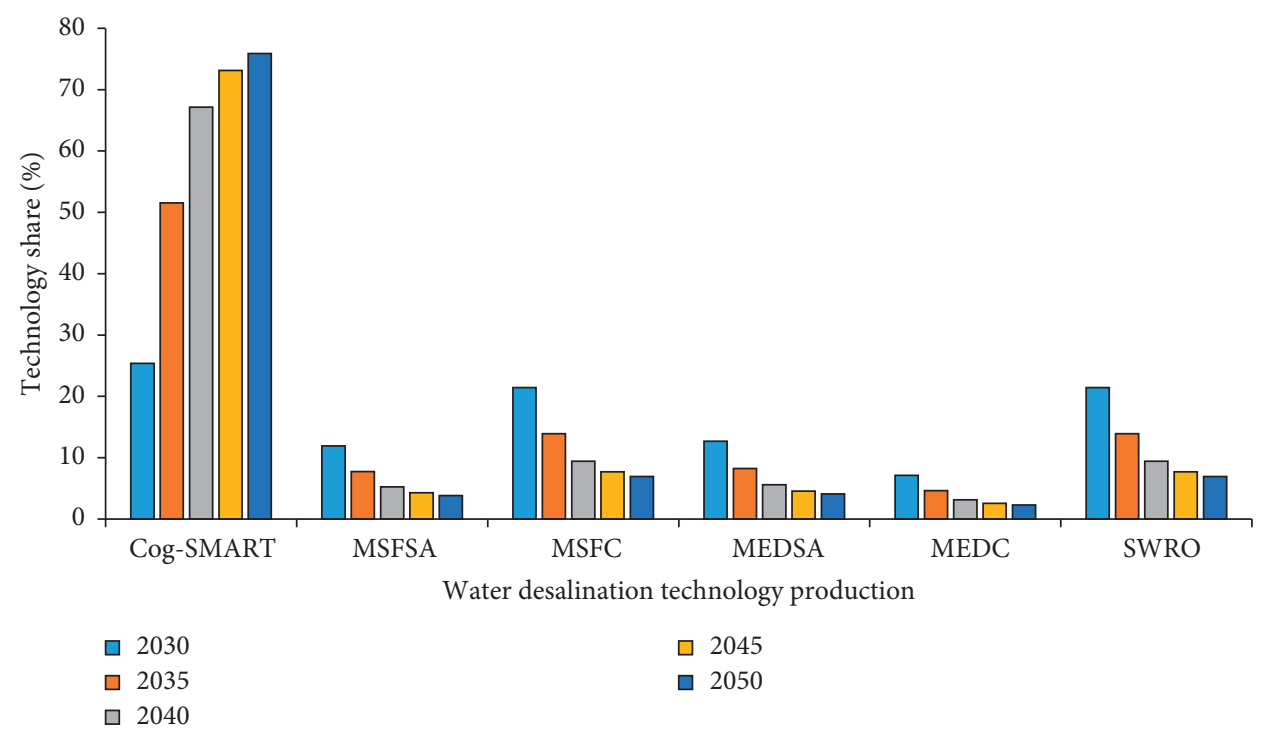

FIGURE 13: Water desalinated technology share (\%) by Cog-SMART-100 against other technologies.

2050, the MESSAGE tool's predicted capacity of the combined fleet was higher and later reduced to the capacity of only using the APR-1400 reactor. This was attributed to the differences in total costs and other nonmonetary terms between the two options considered by the MESSAGE tool.

The predicted composition (or ratio) of the reactor design in Subscenario III-3 by the number of units of NPPs is shown in Figure 19. The predicted capacity of the combined fleet predicted was only higher than the capacity of the APR1400 reactor. This was attributed to the differences in total costs and other nonmonetary terms between the two options considered by the MESSAGE tool.

The LUEC for each subscenario under Scenario III was calculated using the G4ECONS tool utilizing (3) and employing the IDC calculation in (4). Additionally, the input data detailed in Table 4 was used to verify the relative feasibility of the possible nuclear power options (at least in terms of cost) by the MESSAGE tool. The calculated LUECs of predicted nuclear power capacity for Subscenarios III-1, III-2, and III-3 are shown in Figure 20, along with the results 


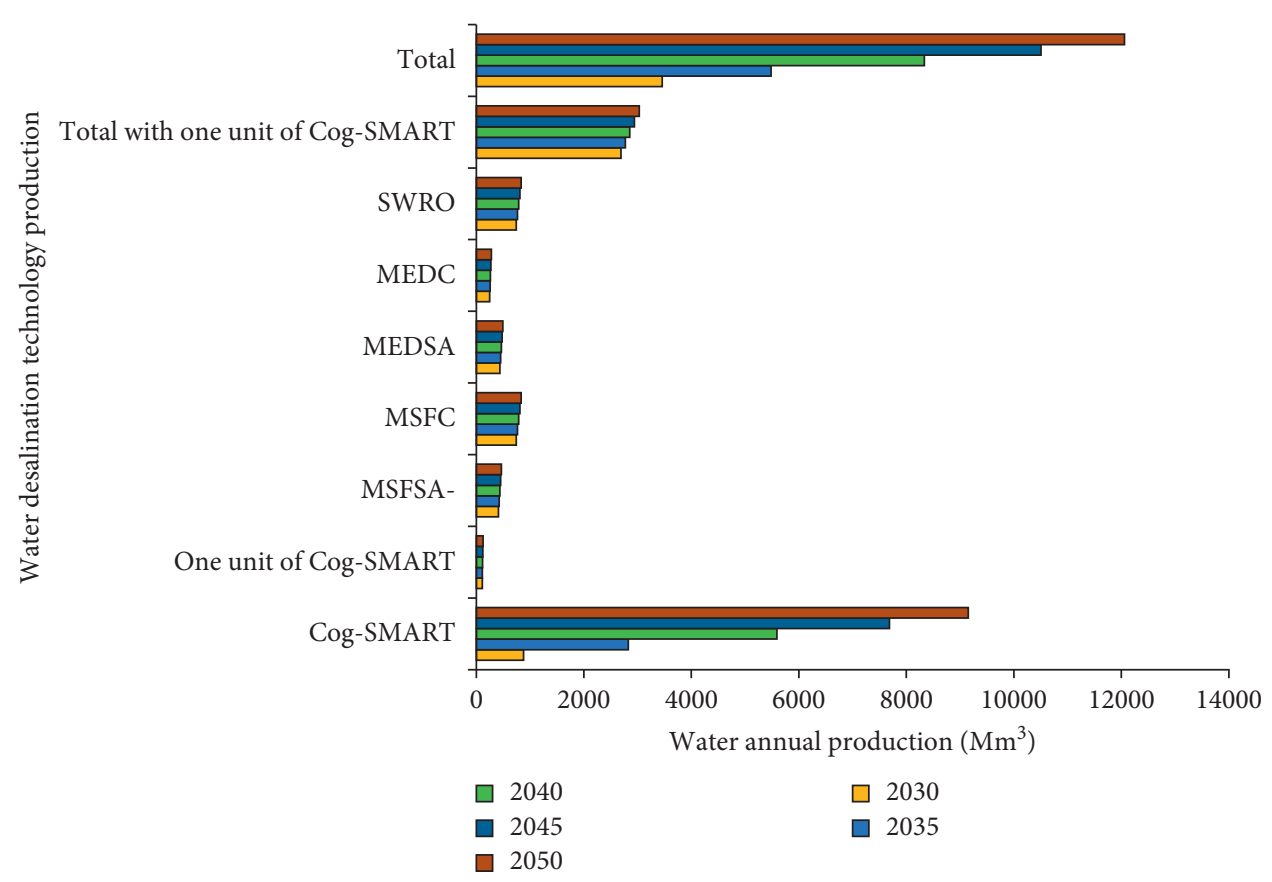

Figure 14: Annual water desalinated $\left(\mathrm{Mm}^{3}\right)$ by Cog-SMART-100 against other technologies.

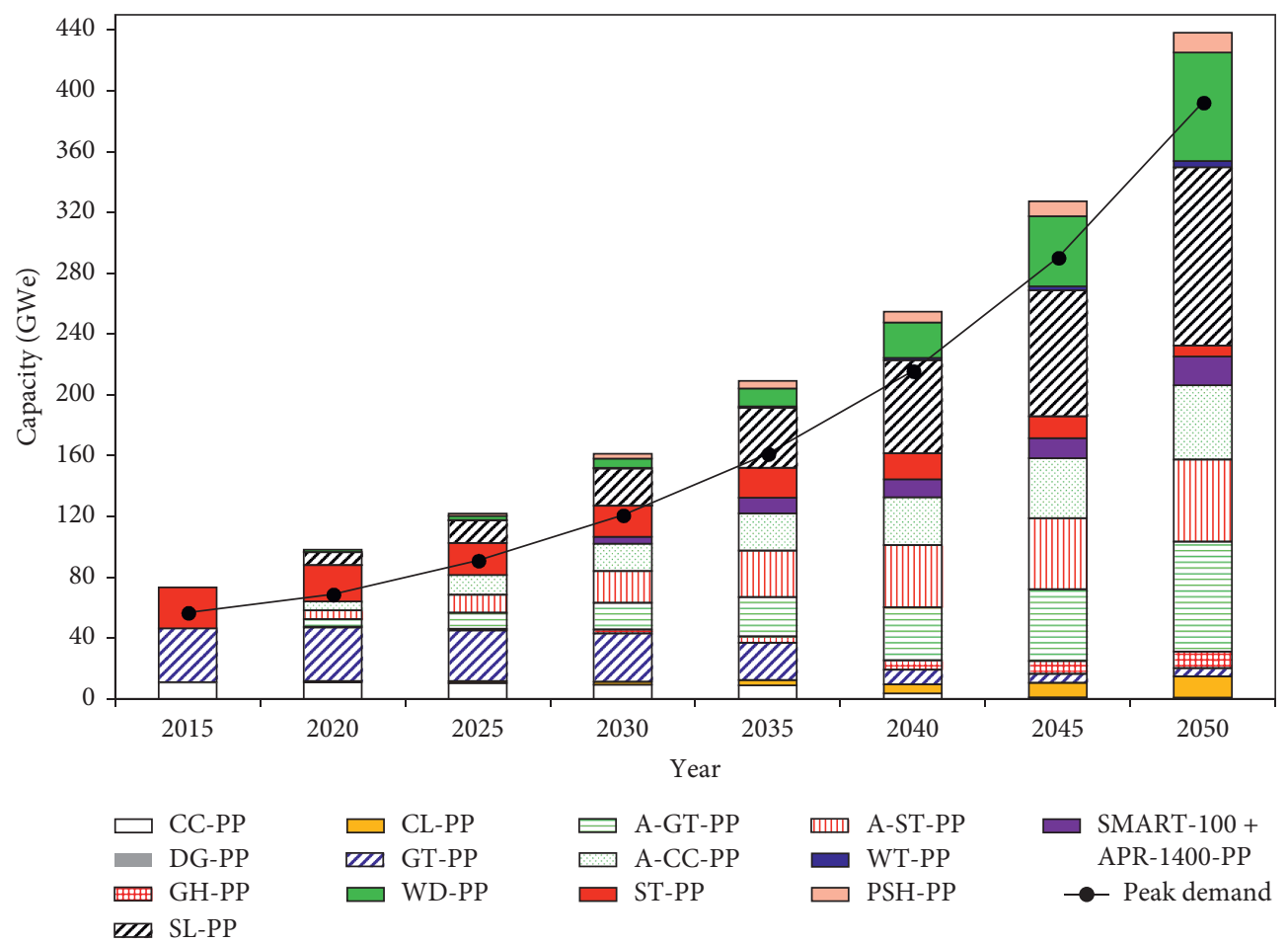

Figure 15: Simulation results from MESSAGE tool for Subscenario III-3.

from the existing studies on the levelized cost of the APR1400 and SMART-100 reactors [40-58].

In this study, the calculated LUEC for the APR-1400 reactor (42.3 U\$/MWh) was slightly higher than the reported values (22.1 to $34.1 \mathrm{U} \$ / \mathrm{MWh}$ ) [50, 94]. However, the calculated LUEC for the SMART-100 reactor (44.3 U\$/MWh) was within the range of the reported values (42 to $78 \mathrm{U} \$ / \mathrm{MWh}$ ) [94-99]. In general, the calculated LUECs for the nuclear energy technologies calculated in this study were comparable to those reported in previous studies. The gaps, including overestimation of the LUEC for the APR-1400 reactor, were attributed to different parameter values, including cost elements and assumed conditions [51]. Furthermore, the increasing 


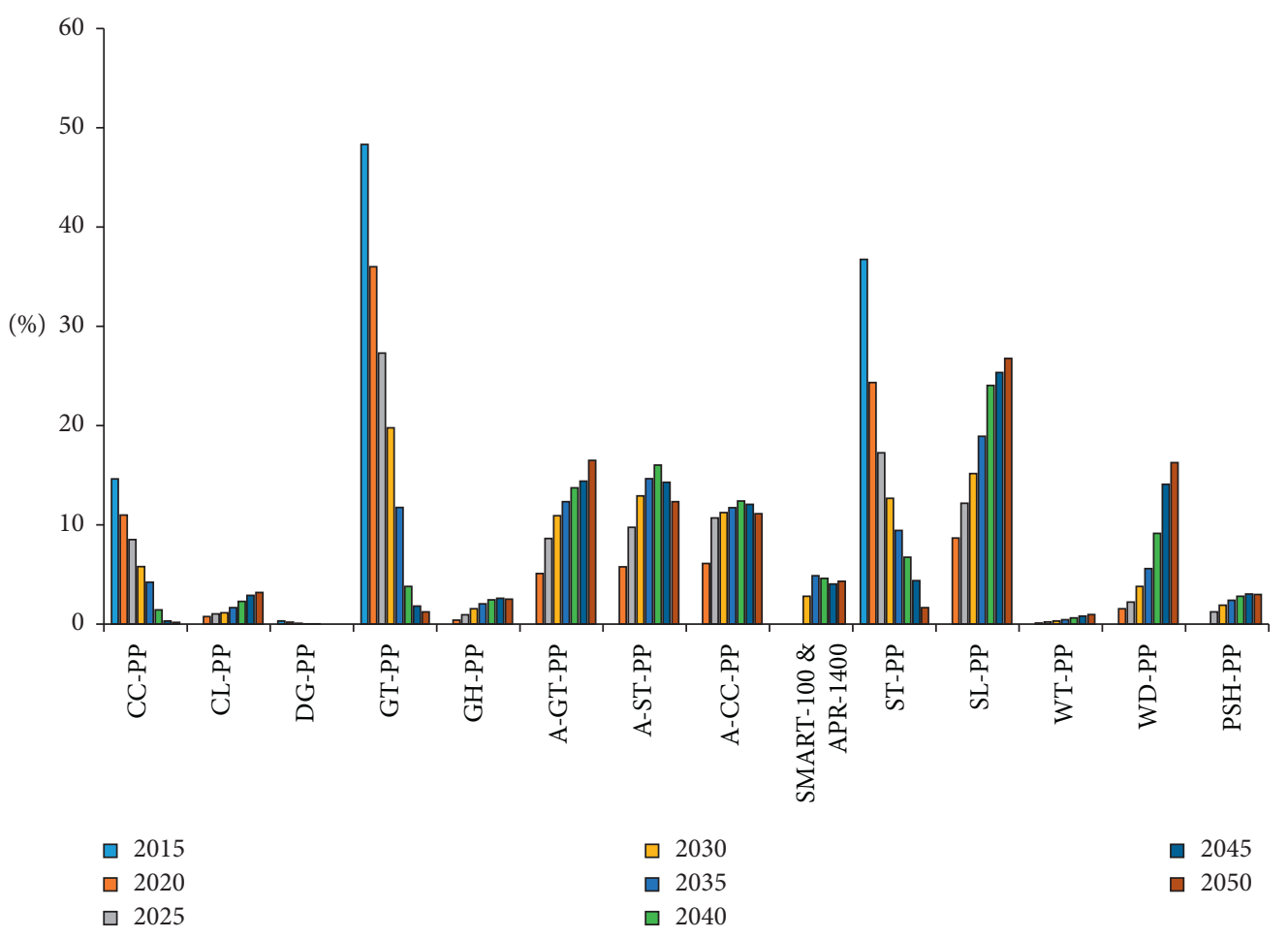

FIGURE 16: Share of power plant technologies for Subscenario III-3.

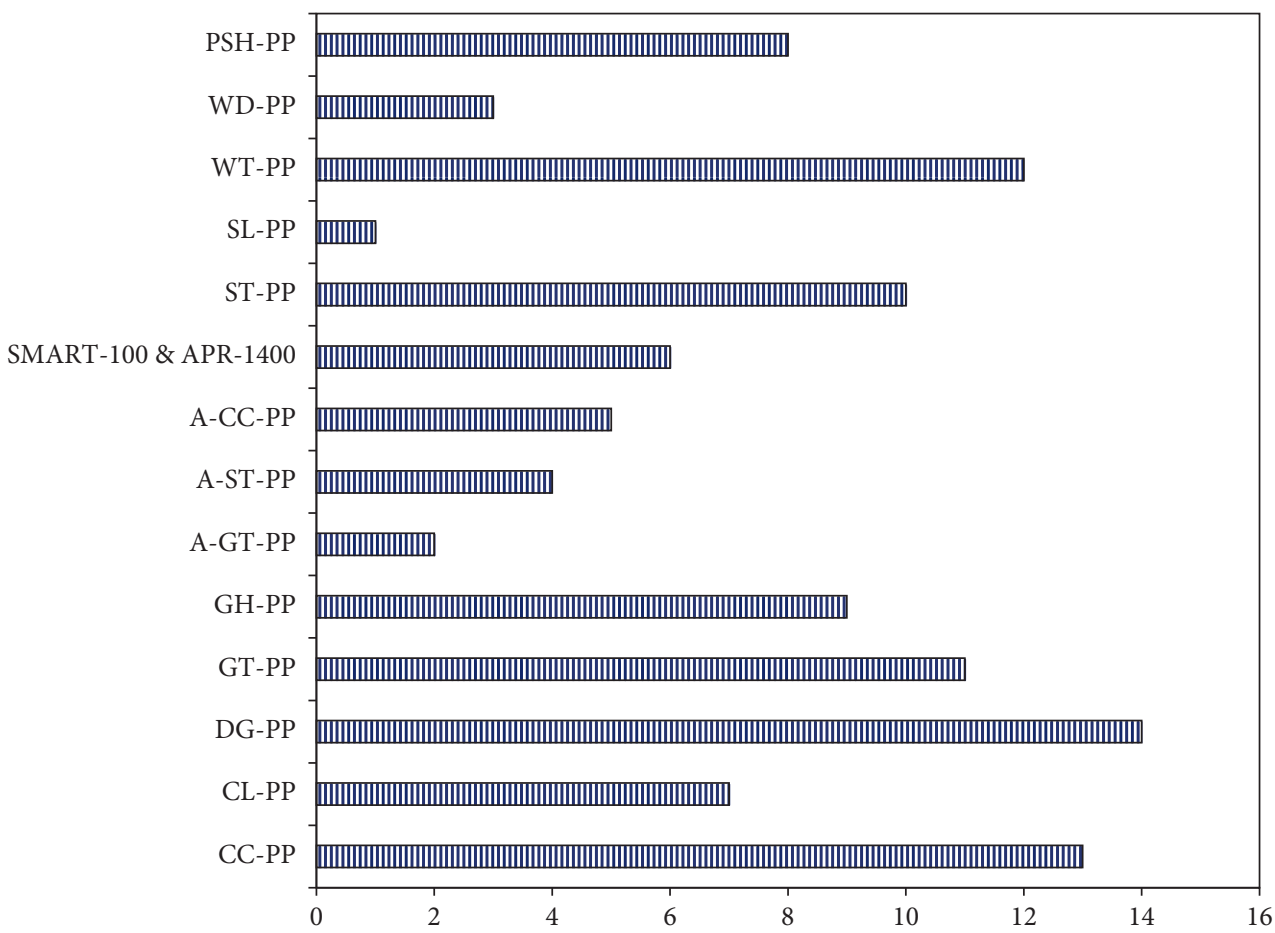

FIGURE 17: Ranking of power plant technologies by 2050 for Subscenario III-3.

order of calculated LUECs for the APR-1400 and SMART-100 reactors in this study were consistent with the decreasing order of the installed capacities of the PPs in Subscenarios III-1 and III- 2 by the MESSAGE tool (see Figures 7 to 15).
The installed capacity of the combined fleet in Subscenario III-3 (18.9 GWe) was $4.3 \%$ higher than the installed capacity of only the APR-1400 reactor in Subscenario III-1 $(16.8 \mathrm{GWe})$ at the end of 2050, as predicted by the MESSAGE tool. However, it should not be interpreted that the 


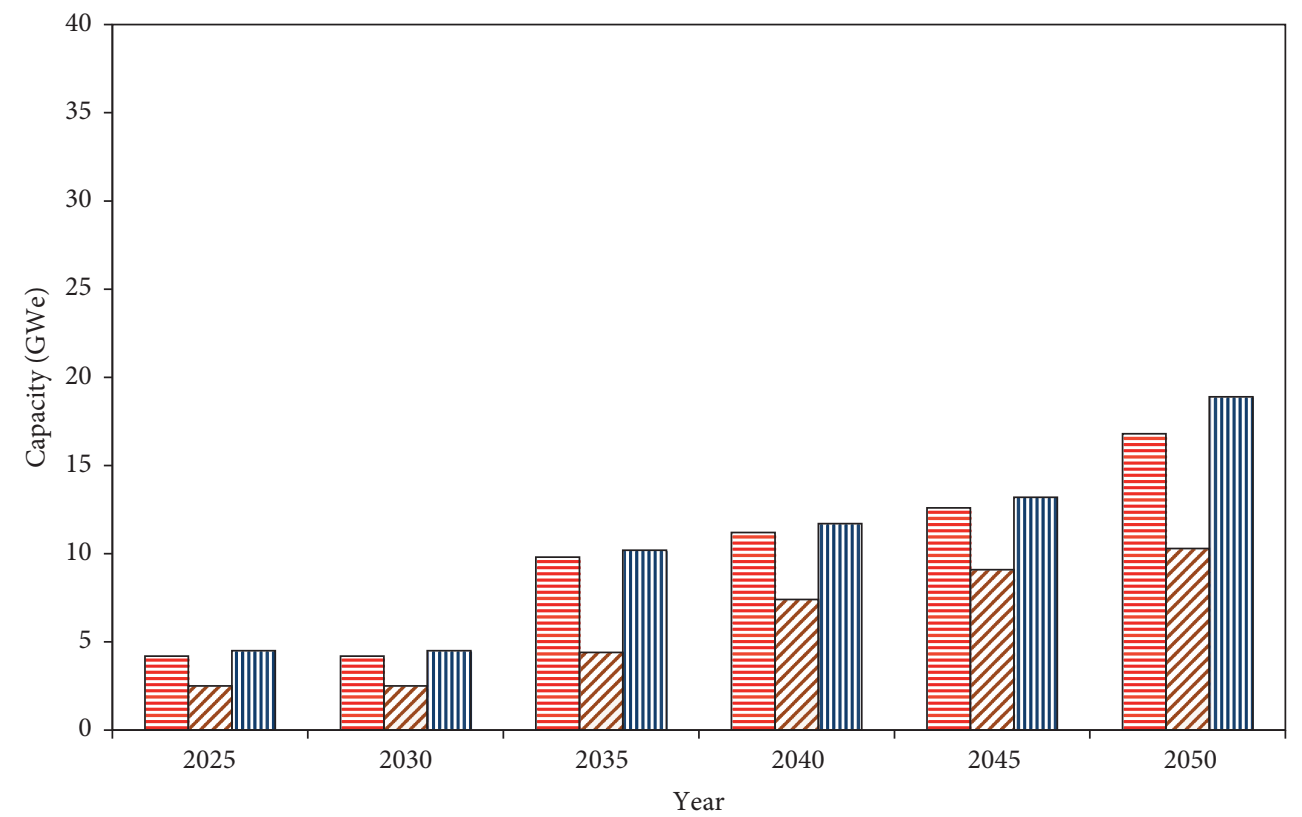

E Scenario III-1

Scenario III-2

m Scenario III-3

FIGURE 18: Installed capacity of nuclear power predicted by MESSAGE tool for Subscenarios III-1 to III-3.

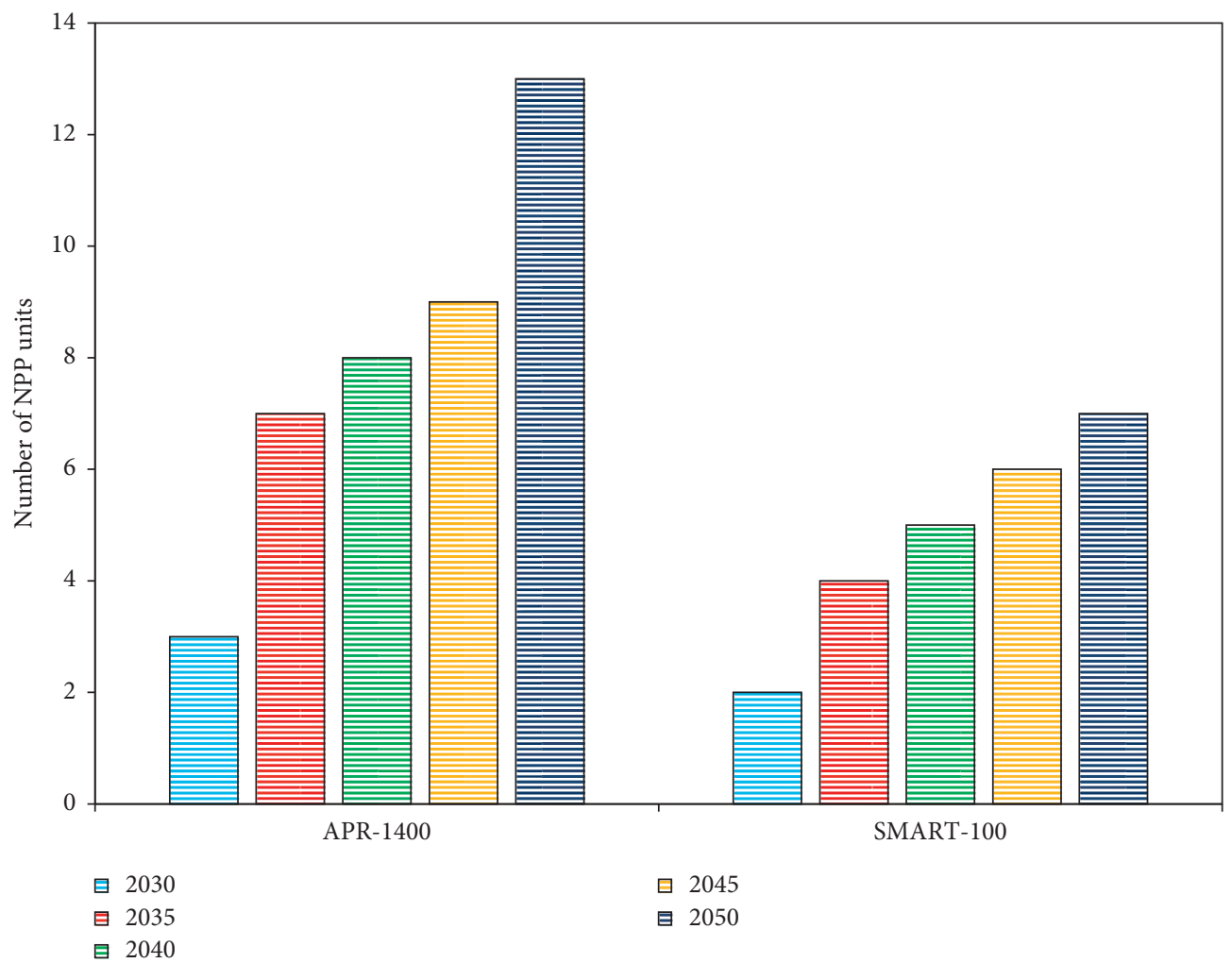

FIgURE 19: Composition (or ratio) of reactor design in Subscenario III-3. 


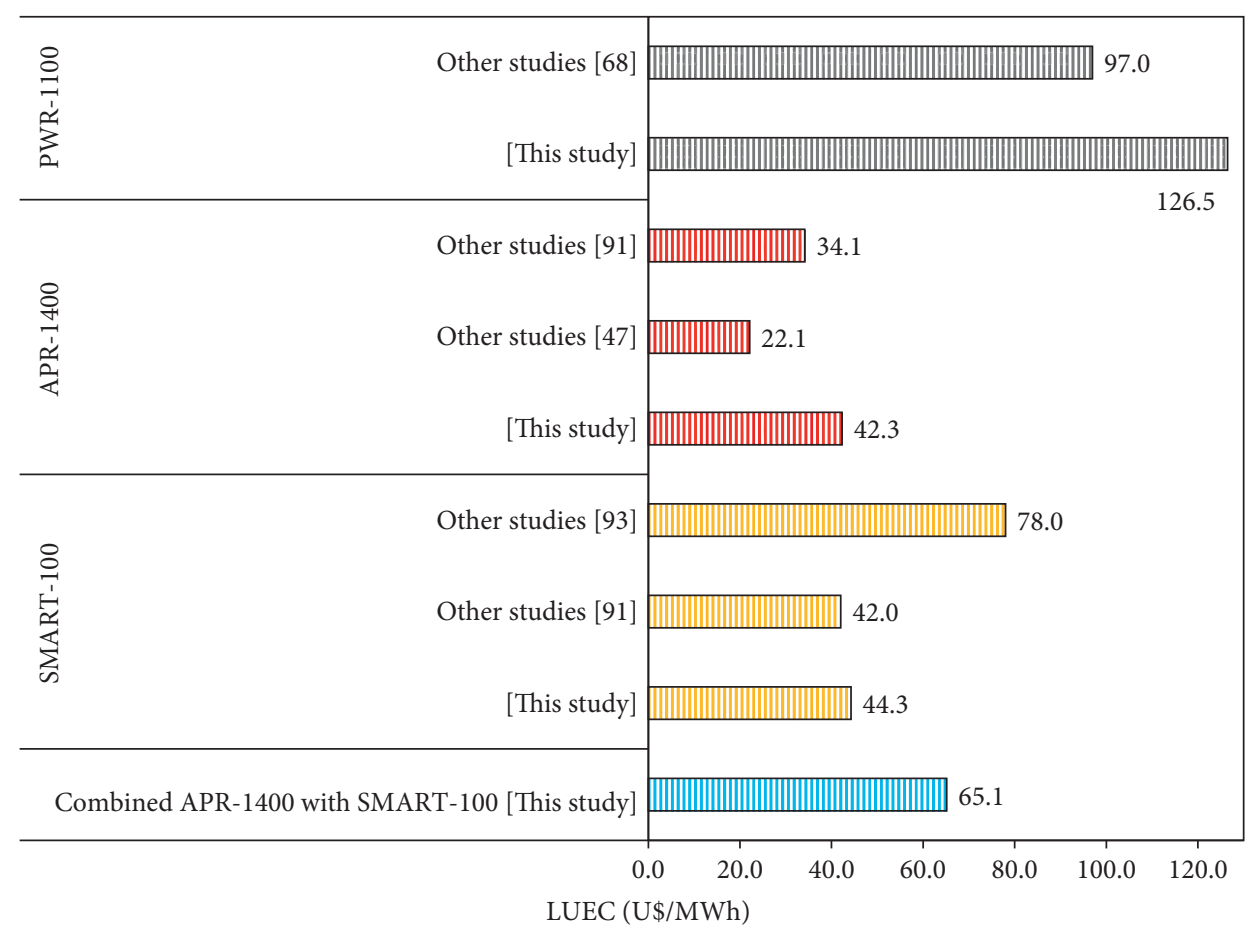

FIGURE 20: LUECs calculated for APR-1400, SMART-100, and the combined nuclear fleet with a ratio of number units of reactors (i.e., 20 : 12 for APR-1400 to SMART-100 as predicted by MESSAGE tool at the end of 2050) along with the LUECs reported in previous studies.

calculated LUEC for the combined nuclear fleet of APR1400 and SMART-100 reactors (65.1 U\$/MWh) was 35\% higher than the calculated LUEC of only using the APR-1400 reactor (42.3 U\$/MWh). Additionally, the IDC showed little effect on the LUEC (i.e., increasing the IDC percentage). The IDC caused a slight reduction in the LUEC, as shown in Figure 21.

However, this reduction did not affect the LUEC for all types of reactors. Even if the reason for the discrepancy could not be specified, it was attributed to additional factors. For example, the region-by-region data used in the MESSAGE tool (see Table 2) may have induced discrepancies in the simplified LUEC calculations that would not have occurred if a national level calculation was performed. In contrast, it might have been necessary to differentiate already commercialized NPPs (e.g., the APR-1400 reactor from the SMART-100 reactor) which has not yet been constructed compared to the relative feasibilities of the nuclear fleet.

The potential reduction in the capacity of the SMART100 first-of-a-kind nuclear reactor was assumed to occur after commercialization $[48,50,51,91,93]$. Capital costs and the operation and maintenance costs of the APR-1400 reactor can be confidently constrained in a range based on previous construction and operation experiences. Thus, the LUECs for the combined nuclear fleet were further estimated by varying the capital cost of the SMART-100 reactor, while other cost factors were kept fixed, as detailed in Table 4 . The composition of the reactor designs is shown in Figure 22. The LUEC of the combined nuclear fleet slightly decreased with a reduction in the capital cost of the SMART100 reactor. The slope of the LUEC was slightly steeper for a higher number of APR-1400 units than SMART-100 units (i.e., they appear as the same line).

The economic feasibility of the combined nuclear fleet and the single APR-1400 reactor in terms of LUEC were reversed in the ranged from 2487.3 to $2822.7 \mathrm{U} \$ / \mathrm{MWe}$ of the capital cost of the SMART-100 reactor (i.e., 71.8\%-75.1\% lower than the reference value listed in Table 4). Below 2822.7, the combined nuclear fleet became more feasible, at least in terms of economics (i.e., LUEC). The capital cost reductions were higher than the reported expectation of capital cost reduction for the SMART-100 reactor (i.e., 15\%55\%) [51-56, 96-99]. For reference, the MESSAGE tool predicted that a higher installed nuclear capacity in Subscenario III-3 than in Subscenario III-1. This prediction would change if the capital cost of the SMART-100 reactor exceeded $10000 \mathrm{U} \$ \mathrm{MWe}$ (i.e., 9.3\% higher than the reference value in Table 4). If that occurred, additional factors would have been taken into consideration.

3.4. Scenario IV (Consideration of Carbon Dioxide Emission). The $\mathrm{CO}_{2}$ emission tax for a power plant was calculated using (2). The $\mathrm{CO}_{2}$ emission tax was additionally reflected in the Subscenarios III-1, III-2, and III-3. Subscenarios IV-1, IV-2, and IV-3 were established. However, SL-PP, WD-PP, and NPP turned out to be positively affected by the $\mathrm{CO}_{2}$ emission tax policy and decreased during the years 2030 to 2050. Specifically, SL-PP increased from 2.2 to 16.7 GWe, WD-PP increased from 1.8 to $7.9 \mathrm{GWe}$, PSH-PP increased from 0.3 to $1.9 \mathrm{GWe}$, and NPP increased from 1.7 to $14 \mathrm{GWe}$. However, the shares of ST-PP, DG-PP, CL-PP, GT-PP, and CC-PP decreased with $\mathrm{CO}_{2}$ taxation. The $\mathrm{CO}_{2}$ taxation for 


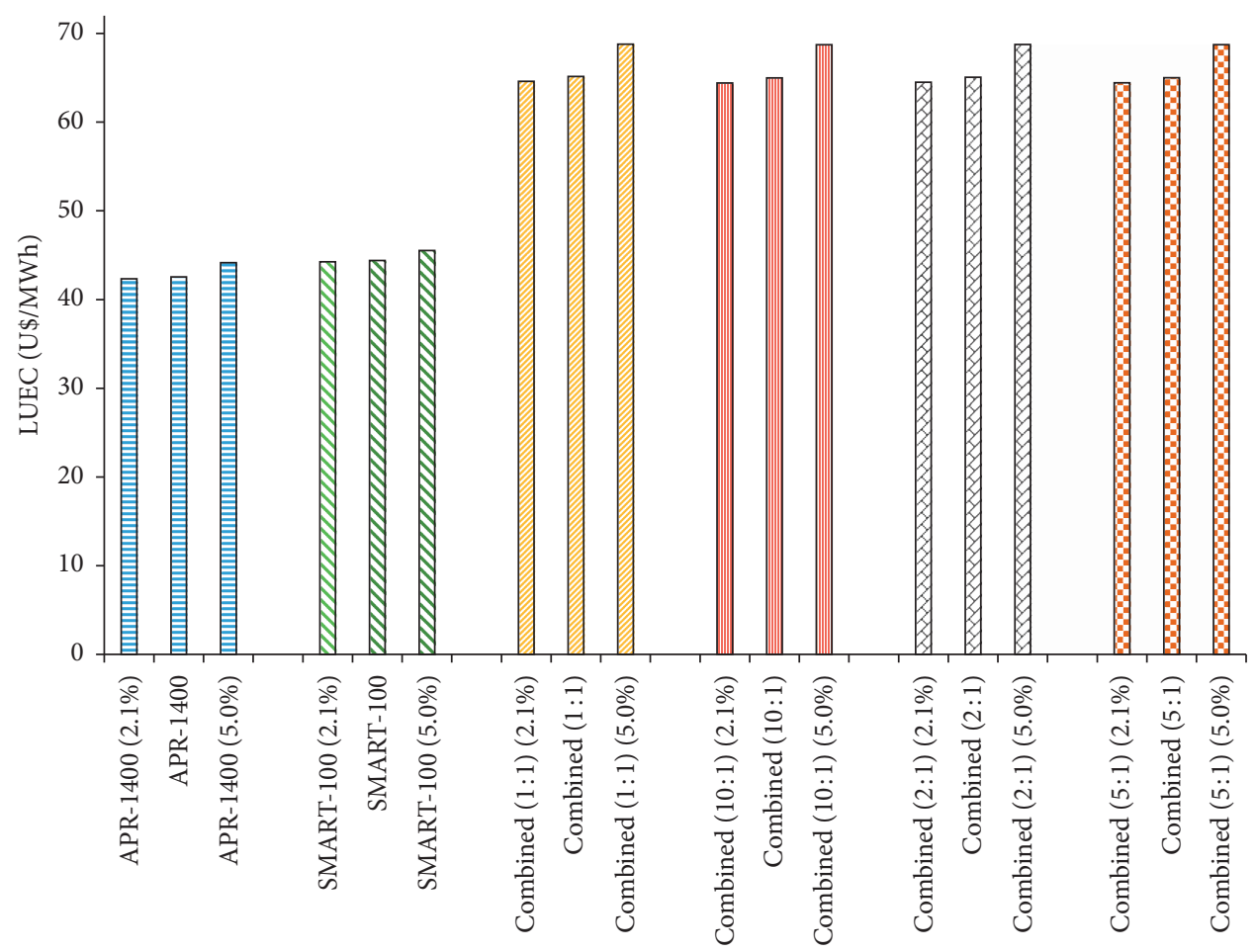

FIGURE 21: The effect of changing the IDC discount rate ratio of the LUECs for each reactor design (i.e., 2.1\%, 2.5\%, 5\%) of the single reactor (APR-1400 and SMART-100) and the combined nuclear fleet (APR-1400 and SMART-100) for the different compositions of reactor designs with varying capital cost of the SMART-100 reactor. Numbers in parenthesis $(X: Y)$ represent the composition of reactor designs (i.e., $X$ units of APR-1400 and $Y$ units of SMART-100).

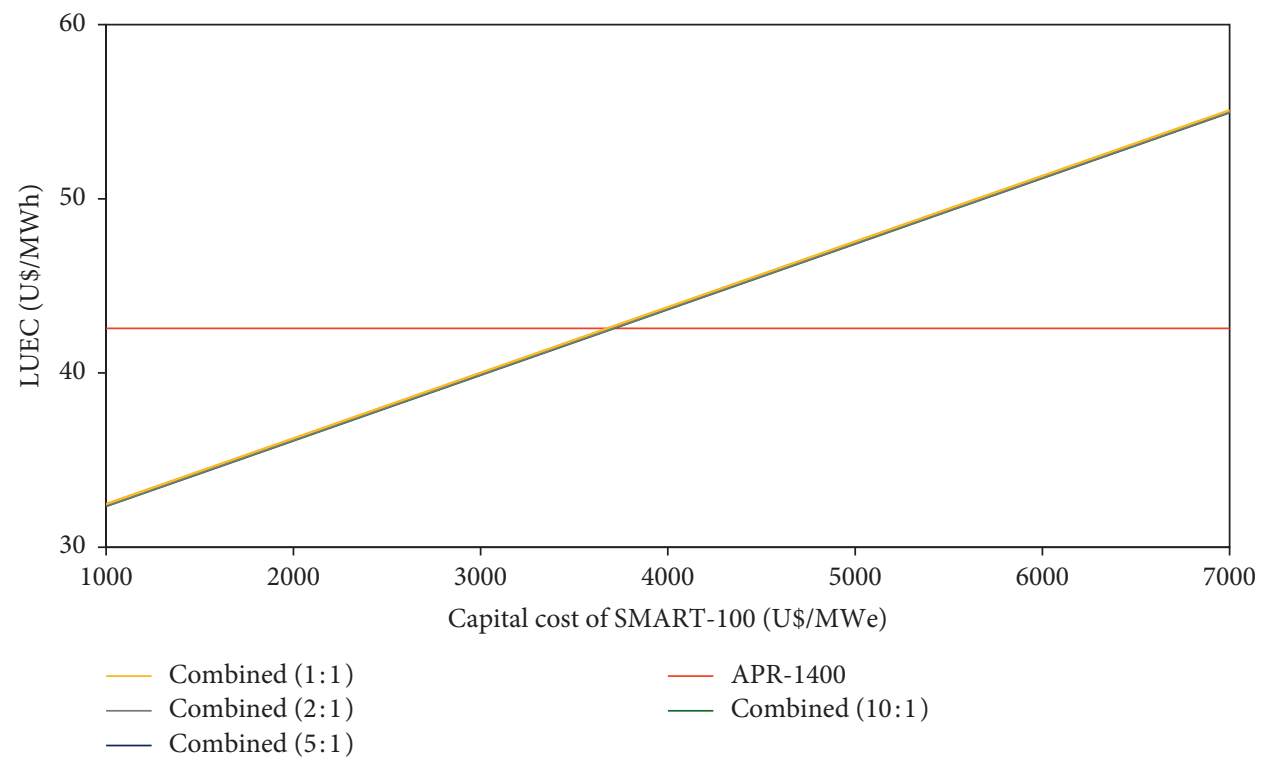

FIGURE 22: Variations in the LUECs of the combined nuclear fleet (APR-1400 and SMART-100) with different compositions of reactor designs and varying capital cost of the SMART-100 reactor. Numbers in parenthesis $(X: Y)$ represent the composition of reactor designs (i.e., $X$ units of APR-1400 and Y units of SMART-100).

each nuclear power option's installed capacity was simulated using the MESSAGE tool. The results are displayed in Figure 23.

As shown in Figure 23, the $\mathrm{CO}_{2}$ taxation policy increased the capacity of all nuclear power options from 2025 to 2050 in Subscenarios IV-1, IV-2, and IV-3 in the range of $8 \%$ to $74 \%$. For example, the $\mathrm{CO}_{2}$ taxation caused expansion of the installed capacity by $67.8 \%$ of the single APR-1400 in Subscenario III- 1 and $74.1 \%$ of the combined nuclear fleet in Subscenario III-3. 


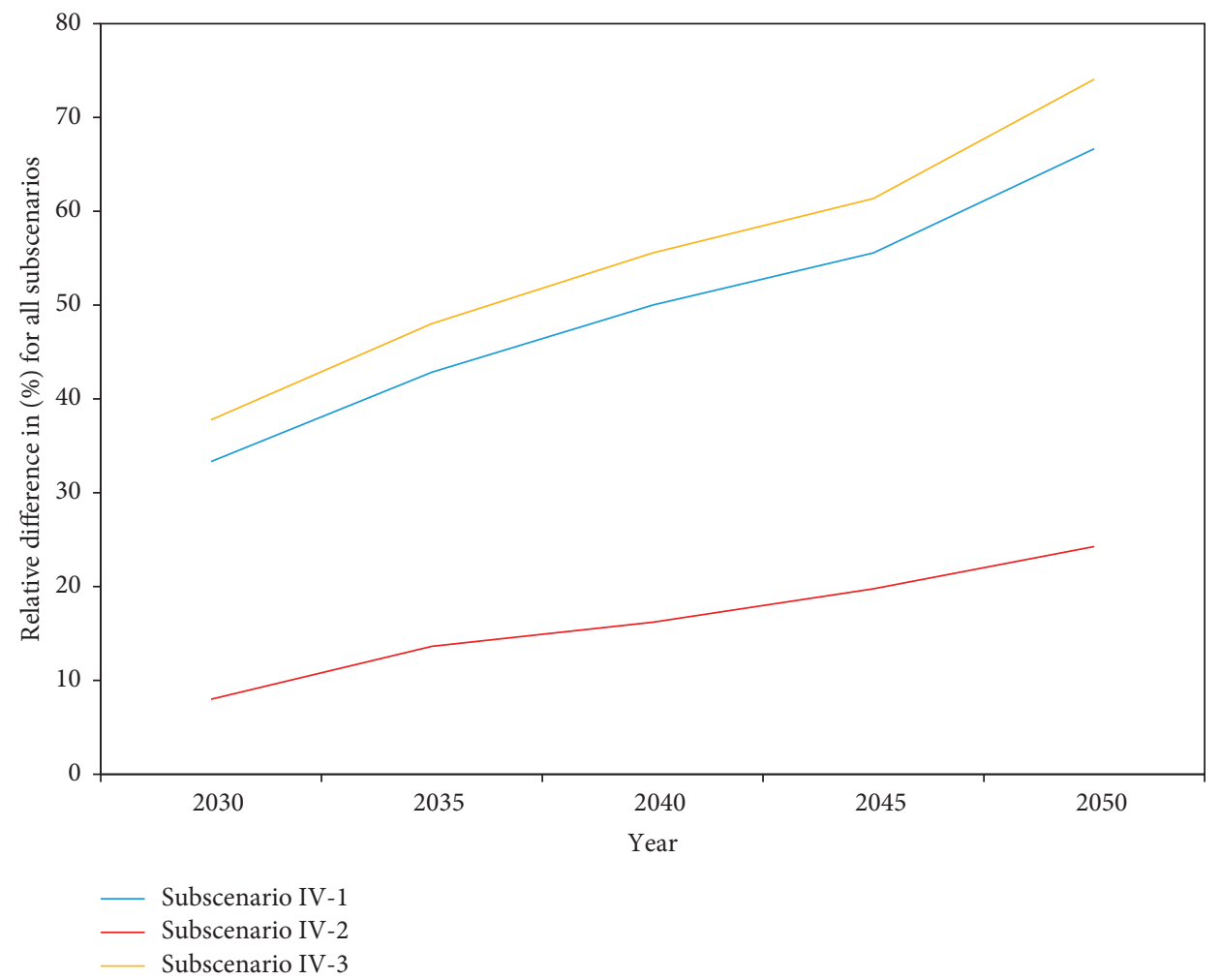

FIGURE 23: Percentage of increased capacity of each nuclear power option after $\mathrm{CO}_{2}$ taxation predicted from MESSAGE tool in Subscenarios IV-1 to IV-3.

\section{Conclusions}

A simplified energy system diagram for Saudi Arabia was established and implemented by collecting the national energy resources distribution system and the energy policy, including the NEDRM and other analyses. In Saudi Arabia, the $2015 \mathrm{EPD}$ of $56.7 \mathrm{GWe}$ as of 2015 was estimated to gradually expanded to 392.4 GWe in 2050. The following scenarios were modeled using a well-known MESSAGE tool to investigate the optimal electricity supply options for Saudi Arabia: (1) reference supply scenario, (2) rehabilitation scenario, and (3) adoption of new energy technologies after 2020 and introduction of nuclear power after 2030 scenario. It was shown that the present Saudi Arabian energy system could cover the predicted electricity demand through 2025 but would experience blackouts thereafter. The rehabilitation of existing PPs could postpone the possible electricity shortage by approximately ten years. However, simply rehabilitating the existing PPS cannot meet the future EPD in Saudi Arabia. The EPD in Saudi Arabia was predicted to continuously expand until the end of 2050 (i.e., the end of this study's timeframe). It was also shown that introducing various candidate new energy technologies, including nuclear power, was needed to generate a sustainable electricity supply in the future for Saudi Arabia. It was predicted that solar, advanced gas, wind, advanced steam, and advanced combined cycle would be the top five major energy technologies in the future. In this study, nuclear power ranked eleventh, and the installed capacity ranked sixth by the end of 2050 . Four subscenarios that assumed a single reactor design (i.e., APR-1400 only or SMART-100 only) and a combined nuclear fleet of APR-1400 and SMART-100 were simulated using the MESSAGE tool to investigate a more strategic nuclear program for Saudi Arabia. The simulation predicted that the combined nuclear fleet would show the highest installed capacity, followed by APR1400 only and SMART-100 only. The decreasing order of capacity for APR-1400 only and SMART-100 only results were partially verified by calculated LUEC for each reactor design generated by the G4ECONS tool. However, the approximately $35 \%$ difference between the capacity of the combined nuclear fleet and the single APR-1400 reactor could not be interpreted only in terms of the LUEC. The calculated LUEC for the combined nuclear power option exceeded the LUEC for the APR-1400 only scenario by approximately $35 \%$. However, the exact reason for the approach feasibility of the combined nuclear fleet could not be interpreted. However, it was proposed that the approach feasibility of the combined nuclear fleet's installed capacity could be partially demonstrated in terms of LUEC if the capital cost of the SMART-100 reactor was within the range of (2487.3 to $2822.7 \mathrm{U} \$ / \mathrm{MWe})$. This finding is consistent with reported studies on the potential reduction in capital cost of a SMART-100 first-of-akind power plant, after commercialization. Investigation into the potential impact of greenhouse gas taxation policy on each candidate energy technology determined that the capacities of new technologies (e.g., solar) would be the most positively affected by the $\mathrm{CO}_{2}$ taxation. Nuclear power ranked as the second most positively affected technology by $\mathrm{CO}_{2}$ taxation. 
During this study's timeframe, nuclear power showed an 8 to $74 \%$ increase in the installed capacity due to $\mathrm{CO}_{2}$ taxation. The main findings and implications from this study were (1) the determination of a potentially higher preference for combined nuclear fleet over single reactor design and (2) the possible impact of greenhouse gas taxation policy could be referenced when proposing optimal strategic options for embarking nuclear countries. However, in this study, each energy technology's relative feasibility, including nuclear power, was based on assumed cost-related parameters. These assumed cost-related parameters are subject to change associated with the uncertainty of the parameter values.

\section{Acronyms}

$\begin{array}{ll}\text { A-CC: } & \text { Advanced combined cycle } \\ \text { A-GT: } & \text { Advanced gas turbine } \\ \text { A-ST: } & \text { Advanced steam } \\ \text { APR: } & \text { Advanced power reactor } \\ \text { CC: } & \text { Combined cycle } \\ \text { CL: } & \text { Coal } \\ \text { Cr: } & \text { Crude oil } \\ \text { CSP: } & \text { Concentrated solar power } \\ \text { D: } & \text { Diesel } \\ \text { DG: } & \text { Diesel generator } \\ \text { EPD: } & \text { Electricity peak demand } \\ \text { FOM: } & \text { Fuel, operation, and maintenance } \\ \text { GT: } & \text { Gas turbine } \\ \text { GH: } & \text { Geothermal } \\ \text { HFO: } & \text { Heavy fuel oil } \\ \text { LUEC: } & \text { Levelized unit energy cost } \\ \text { LPG: } & \text { Liquefied petroleum gas } \\ \text { MESSAGE: } & \text { Model for energy supply strategy alternatives } \\ & \text { and their general environmental impact } \\ \text { NEDRM: } & \text { Nuclear energy development road map } \\ \text { NPPs: } & \text { Nuclear power plants } \\ \text { O\&M: } & \text { Operation and maintenance } \\ \text { OPR: } & \text { Optimal power reactor } \\ \text { PPs: } & \text { Power plants } \\ \text { PV: } & \text { Photo voltage } \\ \text { PSH: } & \text { Pump storage hydro } \\ \text { REI: } & \text { Renewable Energy Institute } \\ \text { SL: } & \text { Solar } \\ \text { SMART: } & \text { System-integrated modular advanced reactor } \\ \text { ST: } & \text { Steam turbine } \\ \text { WNISR: } & \text { World nuclear industry status report } \\ \text { WNA: } & \text { World Nuclear Association } \\ \text { WD: } & \text { Wind } \\ \text { WT: } & \text { Waste. }\end{array}$

\section{Data Availability}

The data used to support the findings of this study are included within the article.

\section{Conflicts of Interest}

The authors declare there are no conflicts of interest regarding this article's publication.

\section{Acknowledgments}

This work was partly supported by "Human Resources Program in Energy Technology" of the Korea Institute of Energy Technology Evaluation and Planning (KETEP), granted financial resource from the Ministry of Trade, Industry \& Energy, Republic of Korea (no. 20184030202170, High Track for Storage and Management Technologies of Nuclear Spent Fuels), and Korea Institute of Energy Technology Evaluation and Planning (KETEP) grant funded by the Korea government (MOTIE) (no. 20203210100240, Development of a Platform for Optimization of Interdependences in Packaging-Transport-Disposal of Radioactive Waste and History Management).

\section{References}

[1] M. E. Bildirici and F. O. Sonustun, "The effects of oil and gold prices on oil-exporting countries," Energy Strategy Reviews, vol. 22, pp. 290-302, 2018.

[2] Y. Hino, Saudi Arabia Field Report Another Potential Oil Crisis in the Middle East, https://www.brookings.edu/blog/markaz/2015/ 07/02/saudi-arabia-field-report-another-potential-oil-crisis-inthe-middle-east/, Brookings Institution, Washington, DC, USA, 2015, https://www.brookings.edu/blog/markaz/2015/07/ 02/saudi-arabia-field-report-another-potential-oil-crisis-in-themiddle-east/.

[3] G. Lahn and P. Stevens, Burning Oil to Keep Cool, the Hidden Energy Crisis in Saudi Arabia, Chatham House, London, UK, 2011.

[4] Enerdata, "Global energy statistical yearbook 2016," 2016, https://yearbook.enerdata.net/electricity/electricity-domesticconsumption-data.html.

[5] A. Arabiya, "Saudi electricity company ranks 14th largest power company globally," Alarabiya News, 2017, https://english. alarabiya.net/business/energy/2017/11/18/Saudi-ElectricityCompany-ranks-14th-largest-power-company-globally.

[6] King Abdullah Petroleum Studies and Research Center (KAPSARC), Electricity Generation by Station Capacities in Saudi Arabia, KAPSARC, Riyadh, UAE, 2021, https://datasource. kapsarc.org/explore/dataset/electricity-generation-by-stationcapacities-in-saudi-arabia/table/?disjunctive.administrative area\&disjunctive.work_area\&disjunctive.station_name\&disjunctive. companies\&disjunctive.primary_fuel\&disjunctive.back_up.

[7] Jeddah Chamber, Index of Sold Energy Consumption in Different Saudi Regions by Sector, Jeddah Chamber, Jeddah, UAE, 2015.

[8] Mordor Intelligence (MI), "Saudi Arabia power marketgrowth, trends, Covid-19 impact, and forecasts (2021-2026)," 2019, https://www.mordorintelligence.com/industry-reports/ saudi-arabia-power-market.

[9] World Nuclear Association (WNA), Nuclear Power in Saudi Arabia, World Nuclear Association, London, UK, 2019, https://www.world-nuclear.org/information-library/countryprofiles/countries-o-s/saudi-arabia.aspx.

[10] M. Walton, Desalinated Water Affects the Energy Equation in the Middle East, International Energy Agency (IEA), Paris, France, 2019, https://www.iea.org/commentaries/desalinatedwater-affects-the-energy-equation-in-the-middle-east.

[11] U. Caldera, D. Bogdanov, S. Afanasyeva et al., "Role of seawater desalination in the management of an integrated water and $100 \%$ renewable energy based power sector in Saudi Arabia," Water, vol. 10, no. 1, 2018. 
[12] A. Al-Gholaikah, N. EL-Ramly, I. Jamjoom, and R. Seaton, "The world's first large seawater reverse osmosis desalination plant, at Jeddah, Kingdom of Saudi Arabia," Desalination, vol. 27 , no. 3, pp. 215-231, 1978.

[13] United Nations Educational, Scientific and Cultural Organization (UNESCO), The United Nations World Water Development Report, UNESCO, London, UK, 2014, https://en. unesco.org/themes/water-security/wwap/wwdr.

[14] E. Jennifer and C. Matt, GE Completes Sale of Water \& Process Technologies Business to Suez, General Electric (GE), Boston, MA, USA, 2017, https://www.ge.com/news/press-releases/gecompletes-sale-water-process-technologies-business-suez.

[15] G. Mantero, G. Lomonaco, and R. Marotta, "Nuclear desalination: an alternative solution to the water shortage," Global Journal of Energy Technology Research, vol. 1, pp. 57-70, 2014.

[16] International Trade Administration, "Saudi Arabia country commercial guide, Saudi Arabia-power," export.gov, https:// www.export.gov/apex/article2?id=Saudi-Arabia-Power, 2018.

[17] International Emissions Agency (IEA), $\mathrm{CO}_{2}$ Emissions from Fuel Combustion Highlights (2019 edition), International Emissions Agency, London, UK, 2019.

[18] A. M. Eltamaly, "Design and implementation of wind energy system in Saudi Arabia," Renewable Energy, vol. 60, pp. 42-52, 2013.

[19] A. Lashin, D. Chandrasekharam, N. Al Arifi, and A. Varun, "Geothermal energy resources of wadi Al-Lith, Saudi Arabia," Journal of African Earth Sciences, vol. 97, pp. 357-367, 2014.

[20] H. E. Khashab and M. A. Ghamedi, "Comparison between hybrid renewable energy systems in Saudi Arabia," Journal of Electrical Systems and Information Technology, vol. 2, no. 1, pp. 111-119, 2015.

[21] A. A. Sharafi, A. Z. Sahin, T. Ayar et al., "Techno-economic analysis and optimization of solar and wind energy systems for power generation and hydrogen production in Saudi Arabia," Renewable and Sustainable Energy Reviews, vol. 69, pp. 33-49, 2017.

[22] S. Griffiths, "A review and assessment of energy policy in the Middle East and North Africa region," Energy Policy, vol. 102, pp. 249-269, 2017.

[23] A. Ahmad, R. Salameh, and M. V. Ramana, Localizing Nuclear Capacity Saudi Arabia and Small Modular Reactors, Issam Fares Institute for Public Policy and International Affairs (IFI), at the American University of Beirut (AUB), Beirut, Lebanon, 2019.

[24] Nuclear Energy Agency (NEA), Technology Roadmap Nuclear Energy 2015 Edition, Nuclear Energy Agency, Paris, France, 2015.

[25] U.S. Government Publishing Office, Implications of a U.S.Saudi Arabia Nuclear Cooperation Agreement for the Middle East, U.S. Government Publishing Office, Washington, DC, USA, Serical No. 115-122, 2018.

[26] REN 21 Renewables Now, Renewables 2019 Global Status Report, REN21, Paris, France, 2019.

[27] A. Gurria, Nuclear Energy in the 21st Century, Nuclear Energy Agency (NEA), Paris, France, 2009, https://www.oecd.org/ environment/nuclearenergyinthe21stcentury.htm.

[28] Nuclear Energy Agency (NEA), Nuclear Energy and Renewables: System Effects in Low-Carbon Electricity Systems, Nuclear Energy Agency (NEA), Paris, France, NEA no. 7056, 2012.

[29] World Nuclear News (WNN), "Korea extends nuclear cooperation to Qatar," 2015, https://www.world-nuclear-news. org/NP-Korea-extends-nuclear-cooperation-to-Qatar0903155.html.
[30] World Nuclear Industry Status Report (WNISR), Grid Connection of First Commercial Reactor in the Arab World, https://www.worldnuclearreport.org/Barakah-UAE-GridConnection-of-First-Commercial-Reactor-in-the-ArabWorld.html, WNISR, Barakah, UAE, 2020, https://www. worldnuclearreport.org/Barakah-UAE-Grid-Connection-ofFirst-Commercial-Reactor-in-the-Arab-World.html.

[31] World Construction Network (WCN), ENEC Completes Construction of Unit 1 at \$32bn Barakah Nuclear Plant in UAE, World Construction Network, London, UK, 2018, https://www.worldconstructionnetwork.com/news/eneccompletes-construction-of-unit-1-at-32bn-barakah-nuclearplant-in-uae/.

[32] D. Proctor, "UAE's first reactor gets go-ahead," Power, https:// www.powermag.com/uaes-first-reactor-gets-go-ahead/, February 2020.

[33] Nuclear Energy Agency (NEA), Small Modular ReactorsNuclear Energy Market Potential for Near-Term Deployment, Nuclear Energy Agency, Paris, France, NEA No.7213, 2016.

[34] M. Aljebrin, "Revisiting electricity consumption function: the case of Saudi Arabia," Business and Economics Journal, vol. 5, no. 4, 2014.

[35] A. H. Almasoud and H. M. Gandayh, "Future of solar energy in Saudi Arabia," Journal of King Saud University-Engineering Sciences, vol. 27, no. 2, pp. 153-157, 2015.

[36] A. K. Gumgumji and A. M. Osama, "Increasing Renewable Penetration in the Saudi Arabia Electricity System," in Proceedings of the 2013 IEEE Southeastcon, pp. 1-5, Jacksonville, FL, USA, April 2013.

[37] W. Matar, R. Echeverri, and A. Pierru, "The prospects for coal-fired power generation in Saudi Arabia," Energy Strategy Reviews, vol. 13-14, no. 13-14, pp. 181-190, 2016.

[38] International Institute for Applied Systems Analysis (IIASA), MESSAGE, IIASA, Laxenburg, Austria, 2020, https://iiasa.ac. at/web/home/research/researchPrograms/Energy/ MESSAGE.en.html.

[39] L. Rečka, The MESSAGE Model Description, Charles University, Prague, Czechia, 2013.

[40] GEN IV International Forum (GIF), "Portal-FAQ on economic modelling working group (EMWG)," 2019, https:// www.gen-4.org/gif/jcms/c_110588/faq-on-economicmodelling-working-group-emwg\#c_110602.

[41] G. S. Rothwell, The Economics of Future Nuclear Power: An Update of the University of Chicago's 2004 the Economic Future of Nuclear Power, Routledge, London, UK, 2016.

[42] International Atomic Energy Agency, "GIF R\&D outlook for generation IV nuclear energy systems: 2018 update," in The proceedings of the GEN IV International Forum (GIF), Vienna, Austria, March 2019.

[43] D. Connolly, H. Lund, B. V. Mathiesen, and M. Leahy, "A review of computer tools for analysing the integration of renewable energy into various energy systems," Applied Energy, vol. 87, no. 4, pp. 1059-1082, 2010.

[44] D. K. Mohapatra and P. Mohanakrishnan, "A methodology for the assessment of nuclear power development scenario," Energy Policy, vol. 38, no. 8, pp. 4330-4338, 2010.

[45] S. M. C. Fairuz, M. Y. Sulaiman, C. H. Lim et al., "Long term strategy for electricity generation in Peninsular Malaysia analysis of cost and carbon footprint using MESSAGE," Energy Policy, vol. 62, pp. 493-502, 2013.

[46] M. Moore, L. Leung, and R. Sadhankar, "An economic analysis of the canadian SCWR concept using G4-ECONS," Canadian Nuclear Laboratories (CNL) Nuclear Review, vol. 5, no. 2, 2016. 
[47] Organization for Economic Co-Operation and Development (OECD), "Cost estimating guidelines for generation IV nuclear energy systems revised 4.2," in Proceedings of theThe Economic Modeling Working Group of the Generation IV International Forum, Paris, France, September 2007.

[48] International Energy Agency (IEA), Projected Costs of Generating Electricity 2020 Edition, IEA, Arlington, VA, USA, 2020.

[49] G. Rothwell, Defining Plant-Level Costs, Nuclear Energy Agency (NEA) International Workshop, OECD, 2016.

[50] Energy Innovation Reform Project (EIRP), What Will Advanced Nuclear Power Plants Cost?: A Standardized Cost Analysis of Advanced Nuclear Technologies in Commercial Development", 2017.

[51] K. D. Han and M. S. Roh, Economic Assessment of SMART Deployment in Korea Using DEEP 5.1, Korean Nuclear Society (KNS) 2015 Autumn meeting October, Gyeongju, South Korea, 2015.

[52] M. H. Chang and S. H. Kim, "Approach for Smart Application to Desalination and Power Generation," Korea Atomic Energy Research Institute (KAERI), Yuseong, South Korea, 1998.

[53] International Atomic Energy Agency (IAEA), Approaches for Assessing the Economic Competitiveness of Small and Medium Sized Reactors, International Atomic Energy Agency, IAEA nuclear energy series no. NP-T-3.7, 2013.

[54] B. Mignacca and G. Locatelli, "Economics and finance of Small Modular Reactors: a systematic review and research agenda," Renewable and Sustainable Energy Reviews, vol. 118, 2020.

[55] Nuclear Energy Agency (NEA), Unlocking Reductions in the Construction Costs of Nuclear: A Practical Guide for Stakeholders, Nuclear Energy Agency, Paris, France, NEA no. 7530, 2020.

[56] "International Atomic Energy Agency (IAEA)," "Nuclear Technology Review”, 2017.

[57] J. D. Kneifel and D. H. Webb, Life Cycle Costing Manual for the Federal Energy Management Program, National Institute of Standardas and Technology (NIST), NIST HB-135-2020, 2020.

[58] Nuclear energy Agency (NEA), Current Status Technical Feasibility and Economics of Small Nuclear Reactors, Nuclear Energy Agency, Paris, France, 2011.

[59] Ministry of Energy Industry and Mineral Resources (MEIM), Petroleum Statistics, Ministry of Energy Industry and Mineral Resources, Riyadh, UAEhttps://www.moenergy.gov.sa/ arabic/Energy/Pages/petroleum-statistics.aspx.

[60] Energy (MESSAGE), Institute for Applied Systems Analysis (IIASA), Laxenburg, Austria.

[61] US Energy Information Administration (EIA), Country Analysis Brief, US Energy Information Administration, Washington, DC, USA, 2020.

[62] A. Hainoun, M. Seif Aldin, and S. Almoustafa, "Formulating an optimal long-term energy supply strategy for Syria using MESSAGE model," Energy Policy, vol. 38, no. 4, pp. 1701-1714, 2010.

[63] General Authority for Statistics Kingdom of Saudi Arabia, Statistical Yearbook of 2019, vol. 55, General Authority for Statistics, Riyadh, UAE, 2019, https://www.stats.gov.sa/en/1006.

[64] US Inflation Calculator, "Current US inflation rates: 20002021,” 2021, https://www.usinflationcalculator.com/inflation/ current-inflation-rates/.

[65] The White House, "M-21-09: 2021 discount rates for OMB circular no. A-94,” December 2020, https://www.whitehouse. gov/omb/information-for-agencies/memoranda/.
[66] R. M. Cumberland, K. A. Williams, J. J Jarrell et al., Cost Sensitivity Analysis for Consolidated Interim Storage of Spent Fuel: Evaluating the Effect of Economic Environment Parameters, " Oak Ridge National Laboratory (ORNL), Oak Ridge, TN, USA, 2016.

[67] W. Matar and M. Anwer, "Jointly reforming the prices of industrial fuels and residential electricity in Saudi Arabia," Energy Policy, vol. 109, pp. 747-756, 2017.

[68] M. Ram, D. Bogdanov, A. Aghahosseini et al., Global Energy System Based on 100\% Renewable Energy-Power Sector, Energy Watch Group, Berlin, Germany, 2017.

[69] F. Alfawzan, J. E. Alleman, and C. R. Rehmann, "Wind energy assessment for NEOM City, Saudi Arabia," Energy Science \& Engineering, vol. 8, no. 2, p. 11, 2019.

[70] International Renewable Energy Agency (IRENA), Renewable Power Generation Costs in 2018, International Renewable Energy Agency, Abu Dhabi, UAE, 2018.

[71] S. J. Zarrouk and H. Moon, "Efficiency of geothermal power plants: a worldwide review," Geothermics, vol. 51, pp. 142-153, 2014.

[72] . International Renewable Energy Agency (IRENA), "Renewable energy technologies: cost analysis series," Power Sector, vol. 1, no. 4-5, 2012.

[73] M. H. Ahmed, M. Arif, T. K. Abdel-Galil et al., "Quantifying the Value of Pumped Storage Hydro (PSH) in the Saudi Electric Grid," in Proceedings of the Saudi Arabia Smart Grid (SASG), pp. 1-6, Jeddah, UAE, December 2016.

[74] Electricity \& Cogeneration Regulatory Authority (ECRA), Annual Statistical Booklet for Electricity and Seawater Desalination Industries, Electricity \& Cogeneration Regulatory Authority, Riyadh, UAE, 2018.

[75] A. Faruqui, R. Hledik, and G. Wikler, Bringing Demand-Side Management to the Kingdom of Saudi Arabia Final Report, The Brattle Group, Boston, MA, USA, 2011.

[76] International Atomic Energy Agency (IAEA), "Model for analysis of energy demand (MAED-2)," Computer Manual Series no. 18, International Atomic Energy Agency, Vienna, Austria, 2006.

[77] U. K. Kesieme, N. Milne, H. Aral, C. Y. Cheng, and M. Duke, "Economic analysis of desalination technologies in the context of carbon pricing, and opportunities for membrane distillation," Desalination, vol. 323, pp. 66-74, 2013.

[78] E. Khalil, "Steam power plants," WIT Transactions on State of the Art in Science and Engineering, vol. 42, 2008.

[79] K. Vatopoulos, D. Andrews, J. Carlsson et al., Study on the State of Play of Energy Efficiency of Heat and Electricity Production Technologies, European Commission, Luxembourg City, Luxembourg, 2012, https://setis.ec.europa.eu/system/files/4. Efficiencyofheatandelectricityproductiontechnologies.pdf.

[80] International Renewable Energy Agency (IRENA), Renewables Account for Almost Three Quarters of New Capacity in 2019, International Renewable Energy Agency, Abu Dhabi, UAE, 2020, https://www.irena.org/newsroom/pressreleases/ 2020/Apr/Renewables-Account-for-Almost-Three-Quartersof-New-Capacity-in-2019.

[81] Reuters, "South Korea's KEPCO shortlisted to bid for Saudi Nuclear Project," 2018, https://www.reuters.com/article/ussouthkorea-nuclear-saudi-idUSKBN1JR1GA.

[82] International Atomic Energy Agency (IAEA), The Database on Nuclear Power Reactors, International Atomic Energy Agency, Vienna, Austria, 2018, https://pris.iaea.org/PRIs/ Home.aspx.

[83] M. A. Yahya, Z. Al-Qodah, and C. W. Z. Ngah, "Agricultural bio-waste materials as potential sustainable precursors used 
for activated carbon production: a review," Renewable and Sustainable Energy Reviews, vol. 46, pp. 218-235, 2015.

[84] Expatnetwork, "General eclectic (GE) wins contract to build Waad Al Shamal Power Plant," 2014, https://www. expatnetwork.com/ge-wins-contract-to-build-waad-al-shampower-plant/.

[85] Saudi Gazette, "Saudi Electric Company (SEC) selects GE’s new gas turbines for Riyadh Plant," 2012, https://saudigazette. com.sa/article/17115.

[86] SDG. Knowledge Hub, "Climate transparency report assesses G20's progress towards climate goals," 2018, https://sdg.iisd. org/news/climate-transparency-report-assesses-g20sprogress-towards-climate-goals/.

[87] P. Vithayasrichareon and I. F. MacGill, "A Monte Carlo based decision-support tool for assessing generation portfolios in future carbon constrained electricity industries," Energy Policy, vol. 41, pp. 374-392, 2012.

[88] P. Luckow, E. A. Stanton, B. Biewald et al., 2015 Carbon Dioxide Price Forecast, Synapse Energy Enconomics, Inc., Cambridge, MA, USA, 2015.

[89] C. Komanoff, Power Plant Cost Escalation: Nuclear and Coal Capital Costs Regulations and Economics, Van Nostrand Reinhold Company Inc., New York, NY, USA, 1981.

[90] Nuclear energy Agency (NEA), "The costs of decarburization: system costs with high shares of nuclear and renewables," Nuclear Energy Agency, Paris, France, NEA No. 7299, 2019.

[91] Nuclear Energy Agency (NEA), Nuclear Energy and Renewables: System Effects in Low-Carbon Electricity Systems, OECD Publishing, Paris, France, 2012.

[92] Nuclear Energy Agency (NEA), "Sustainable development and the application of discounting to the calculation of the levelised costs of electricity," Nuclear Energy Agency, Paris, France, NEA/NDC/R(2018)1, 2018.

[93] H. Allcott, A. O'Connell, and S. D. O'Connell, "How do electricity shortages affect industry? Evidence from India," American Economic Review, vol. 106, no. 3, pp. 587-624, 2016.

[94] M. Lee, "Economic Assessment of Smart in Korea," in Proceedings of the International Seminar on Status and Prospects for Small and Medium Sized Reactors, pp. 101-102, Cairo, Egypt, May 2001.

[95] A. J. Seebregts, H. J. M. Snoep, J. Van Deurzen et al., Kernenergie \& Brandstofmix. Effecten van Nieuwe Kerncentrales na 2020 in de kernenergiescenario's uit het Energierapport 2008, Energy Research Centre of the Netherlands, Petten, The Netherlands, 2010.

[96] SMR Start to a Clean Energy Future, The Economics of Small Modular Reactors, September 2017.

[97] C. P. Javier, A. Gustavo, R. Ramón et al., "Levelized costs for nuclear, gas and coal for electricity, under the Mexican scenario," in Proceedings of the Americas Nuclear Energy Symposium, Miami Beach, FL, USA, October 2004.

[98] A. Ahmed and M. V. Ramana, "Too costly to matter: economics of nuclear power for Saudi Arabia," Energy, vol. 69, pp. 682-694, 2014.

[99] International Energy Agency (IAEA), Country Nuclear Power Profiles 2017 Edition, https://www-pub.iaea.org/MTCD/ Publications/PDF/cnpp2017/countryprofiles/

KoreaRepublicof/KoreaRepublicof.htm, Future development of nuclear power, Seoul, South Korea, 2017, https://www-pub. iaea.org/MTCD/Publications/PDF/cnpp2017/ countryprofiles/KoreaRepublicof/KoreaRepublicof.htm. 